\title{
Pathogenic Mechanisms of Myeloma Bone Disease and Possible Roles for NRF2
}

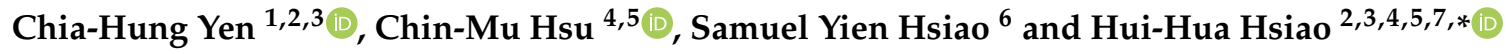 \\ 1 Graduate Institute of Natural Products, College of Pharmacy, Kaohsiung Medical University, Kaohsiung 807, \\ Taiwan; chyen@kmu.edu.tw \\ 2 Center for Cancer Research, Kaohsiung Medical University, Kaohsiung 807, Taiwan \\ 3 Department of Medical Research, Kaohsiung Medical University Hospital, Kaohsiung 807, Taiwan \\ 4 Division of Hematology and Oncology, Department of Internal Medicine, Kaohsiung Medical University \\ Hospital, Kaohsiung 807, Taiwan; e12013@gmail.com \\ 5 Center for Liquid Biopsy, Kaohsiung Medical University, Kaohsiung 807, Taiwan \\ 6 Department of biology, University of Rutgers-Camden, Camden, NJ 08102, USA; ucdsacnyu@gmail.com \\ 7 Faculty of Medicine, Kaohsiung Medical University, Kaohsiung 807, Taiwan \\ * Correspondence: huhuhs@kmu.edu.tw
}

Received: 29 July 2020; Accepted: 12 September 2020; Published: 14 September 2020

\begin{abstract}
Osteolytic bone lesions are one of the central features of multiple myeloma (MM) and lead to bone pain, fractures, decreased quality of life, and decreased survival. Dysfunction of the osteoclast (OC)/osteoblast $(\mathrm{OB})$ axis plays a key role in the development of myeloma-associated osteolytic lesions. Many signaling pathways and factors are associated with myeloma bone diseases (MBDs), including the RANKL/OPG and NF-KB pathways. NRF2, a master regulator of inflammatory signaling, might play a role in the regulation of bone metabolism via anti-inflammatory signaling and decreased reactive oxygen species (ROS) levels. The loss of NRF2 expression in OCs reduced bone mass via the RANK/RANKL pathway and other downstream signaling pathways that affect osteoclastogenesis. The NRF2 level in OBs could interfere with interleukin (IL)-6 expression, which is associated with bone metabolism and myeloma cells. In addition to direct impact on OCs and OBs, the activity of NRF2 on myeloma cells and mesenchymal stromal cells influences the inflammatory stress/ROS level in these cells, which has an impact on OCs, OBs, and osteocytes. The interaction between these cells and OCs affects the osteoclastogenesis of myeloma bone lesions associated with NRF2. Therefore, we have reviewed the effects of NRF2 on OCs and OBs in MBDs.
\end{abstract}

Keywords: nuclear factor erythroid 2-related factor 2 (NRF2); osteoclast; osteoclastogenesis; osteoblast; multiple myeloma; the receptor activator of NF-kappa B (RANK); the receptor activator of NF-kappa $\mathrm{B}$ ligand (RANKL); osteoprotegerin (OPG)

\section{Introduction}

Multiple myeloma (MM), characterized by malicious clonal explanation of plasma cells in the bone marrow with creation of monoclonal gammopathy, is the second most prevalent hematologic malignancy in adults. It accounts for approximately $13 \%$ of all hematologic malignancies and $1 \%$ of all cancers in the world, with a median age of onset of 69 years [1,2]. In addition to plasmacytosis in the marrow and monoclonal protein in serum and/or urine samples, active myeloma is defined by the presence of at least one of the CRAB criteria: Hypercalcemia (calcium $>11 \mathrm{mg} / \mathrm{dL}$ ), renal function insufficiency (creatinine $>2 \mathrm{mg} / \mathrm{dL}$ ), anemia (hemoglobin $<10 \mathrm{mg} / \mathrm{dL}$ ), and bone lesions ( 1 or more skeletal lesions on survey).

Myeloma bone diseases (MBDs) are characterized by lytic lesions caused by an imbalance of bone remodeling due to an increase in bone resorption and a decrease in bone formation. Myeloma cells 
interfere with bone remodeling by stimulating osteoclast (OC) function and inhibit osteoblast (OB) differentiation, which results in osteolytic bone lesions of myeloma patient $[3,4]$. Bone lesions occur in up to $80 \%$ of active disease, and complete repair of bone lesions rarely occurs. These lesions are comprised of osteolytic lesions and/or diffuse osteopenia, even in patients without active disease $[2,5,6]$. In myeloma, bone disease mainly affects the axial skeleton, including the vertebrae (33\%), ribs (15\%), sternum (13\%), and other long bones [7]. It leads to serious complications and/or skeletal-related events (SREs), which include fracture, compression of the spinal cord, hypercalcemia, and the need for further surgical treatment or radiation therapy. SREs not only decrease the quality of life as a result of pain, emotional distress, and treatment procedures, but also affect the survival of MM patients [6,8-10]. Therefore, knowledge of myeloma bone lesions for further disease management is warranted.

The interaction among MM cells, OC, and OB relies on many cytokines/proteins from myeloma cells or osteocytes, which promote OC differentiation via the receptor activator of NF-kappa B ligand (RANKL), chemokine C-C motif 3 (CCL3), interleukin (IL)-1,6, and osteoprotegerin (OPG) [11-13]. On the other hand, myeloma cells also respond to Wnt signaling pathway inhibitors, like dickkopf-1 (DDK-1) and sclerostin, which inhibit OB function [14]. With the imbalance of bone remodeling due to decreased $\mathrm{OB}$ function and increased $\mathrm{OC}$ function, $\mathrm{MM}$ creates a vicious cycle of tumor expansion and bone destruction.

Current management of MBD such as bisphosphonates (BPs) and denosumab reduce further bone destruction by OCs. Thus, they are therapeutic effects are limited due to the inability to actively stimulate bone formation. Therefore, research into the mechanisms involving in the dysregulation of bone remodeling in MM is essential. Nuclear factor erythroid 2-related factor 2 (NRF2) is a key transcription factor regulates the expression of cytoprotective genes against oxidative and chemical insults. In addition, NRF2 also modulates inflammation responses in several cell types. Recently, NRF2 has been shown to be associated with the malignant phenotype of many cancer cells, including myeloma cells. Interestingly, it also contributes to bone remodeling in disease status. Therefore, we summarized the current knowledge of the pathogenesis of myeloma and myeloma bone lesions. We focused on the inflammatory stress and anti-inflammatory mechanism of NRF2 on bone metabolism in myeloma [15].

\section{Bone Metabolism}

The bone tissue has a distinct composition and function in humans. The primary function of the skeletal system is to provide support and movement of the body and protect the internal organs from damage. It also serves as a mineral reservoir and fat repository. Structurally, bone tissues are composed of a series of canals and cavities interlaced with blood vessels which are all housed in a hydroxyapatite and collagen matrix. This allows a heterogeneous mixture of cells such as bone, immune, mesenchymal, and hematopoietic stem cells to exist in proximity to one another [16]. Bone remodeling is a lifetime dynamic process between bone resorption and formation, which is important for preserving bone integrity, sustaining mechanical loading, and maintaining mineral homeostasis. Bone remodeling arises in a basic multicellular unit, where OCs, OBs, and osteocytes act in a coordinated fashion $[17,18]$. All bone cells were constituted $90 \%$ by osteocytes, while OBs and OCs make up less than $10 \%$ of them.

OCs are multinucleated cells derived from the fusion of mononuclear cells of the monocytes-macrophage lineage originating from hematopoietic stem cells. They contain proteins with bone resorption function, such as tartrate-resistant acid phosphatase (TRAP), carbonic anhydrase II, calcitonin receptors, and some cathepsins (lysosomal protease) [19,20]. In order to decompose the bone matrix, OCs bind to the bone surface strongly enough to create an acidic microenvironment and utilize enzymes like metalloproteinase and cathepsin to degrade said matrix structure. The regulation of this decomposition process depends strongly upon the RANK/RANKL/OPG pathway which is a key regulator for OC differentiation and activity [21,22]. The RANK/RANKL pathway induces downstream signaling pathways for differentiation, development, and maturation [23]. RANK, a transmembrane signal receptor, mainly expressed on the OCs surface and its expression can be induced by cytokines 
that stimulate bone resorption, such as parathyroid hormone (PTH), 1,25-dihydroxyvitamin D3, and prostaglandins [24]. In a RANK or RANKL knockout mice study, the animal demonstrated severe osteoporosis due to a lack of OCs [25,26]. OPG is a soluble decoy receptor of RANKL, which inhibits osteoclastogenesis through the RANK/RANKL pathway by blockings the interaction of RANK and RANKL [27]. OPG is released by OBs and bone marrow stromal cells (BMSCs) and is regulated by IL- $1 \beta$, tumor necrosis factor (TNF)- $\alpha$, transforming growth factor (TGF)- $\beta$, and estradiol and $17 \mathrm{~b}$-estriol $[28,29]$. The importance of OPG was demonstrated by the study showing that mice will develop osteopenia and osteoporosis without OPG [13] (Figure 1). The RANKL/OPG ratio is the key for bone osteoclastogenesis; the ratio is low in the normal state, and the ratio becomes abnormal in benign and malignant bone disease [30,31].

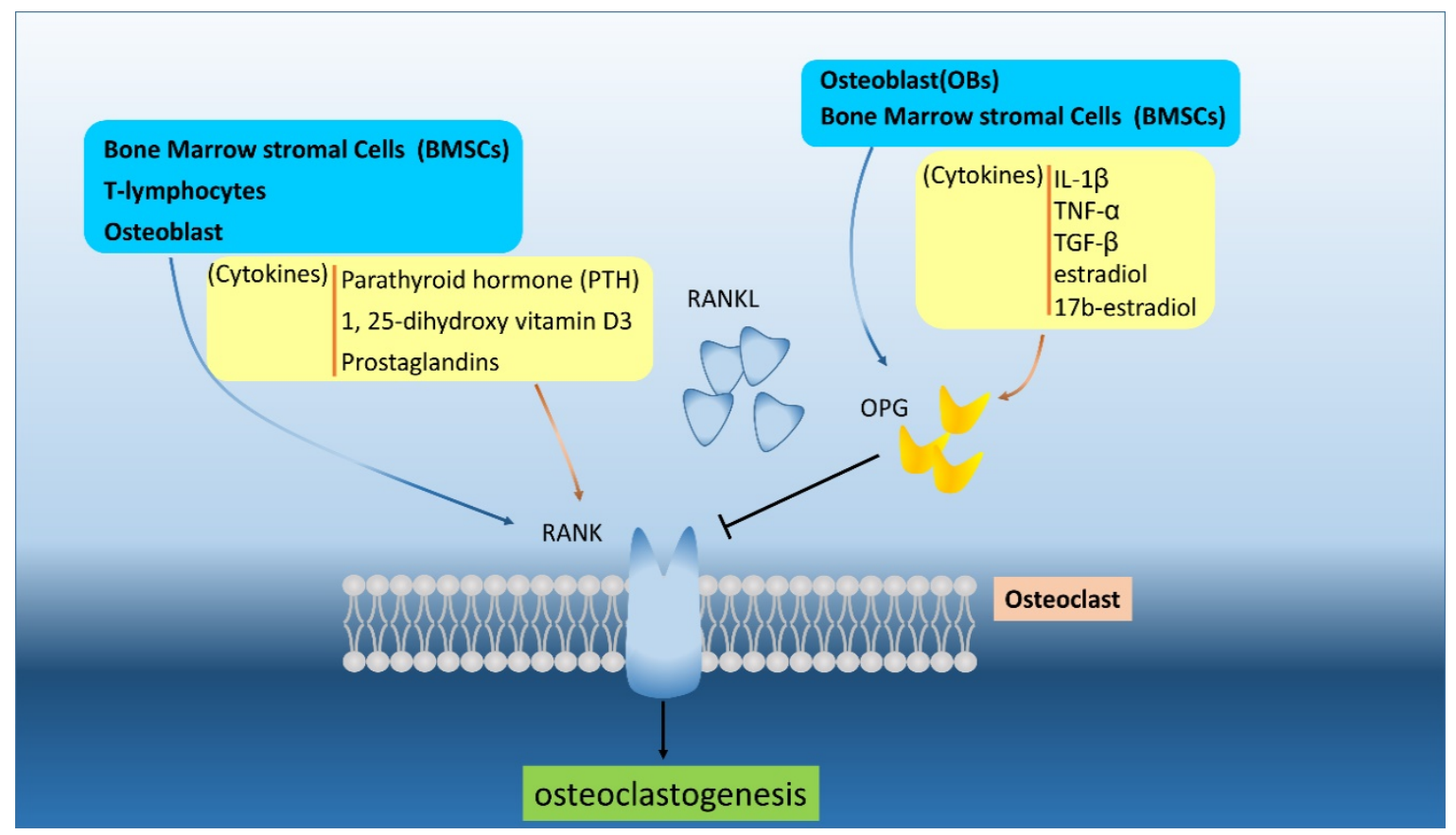

Figure 1. The RANKL/OPG/RANK (receptor activator of NF-kappa B ligand/osteoprotegerin/receptor activator of NF-kappa B) are secreted and regulated by various cells and different cytokines. The RANKL and OPG can be produced by bone marrow stromal cells (BMSCs) and osteoblasts (OBs) to interact or compete RNAK in osteoclast and osteoblast. The OPG can regulated by cytokines, like interleukin (IL)- $1 \beta$, tumor necrosis factor (TNF)- $\alpha$, TGF- $\beta$, estradiol, and 17b-estradiol.

OBs are mononuclear cells originating from mesenchymal stem cells and evolve into osteocytes or bone-lining cells by specific steps [32]. They contain the enzyme alkaline phosphatase for bone formation, which can also be used as a marker of OB activity [33]. They are normally located on the bone surface and lay down new bone [34]. Through collagen formation and the production of osteopontin and osteocalcin, they mineralize the bone matrix and solidifies the bone. The specific differentiation steps of OBs are modulated by the time-dependent expression of transcription factors, such as Runt-related transcription factor 2 (RUNX2), Distal-Less Homeobox 5 (DLX5), and osterix, in the osteoblastogenesis process [32] (Figure 2). Osteoblastogenesis relies on the balance of agonist and antagonist activity of the Wnt signaling pathway, which regulates the expression of the transcription factor beta-catenin [35]. After new bone formation, OBs may serve as lining cells on the bone surface, become osteocytes, embed itself into the mineralized matrix, or simply undergo apoptosis [36]. 


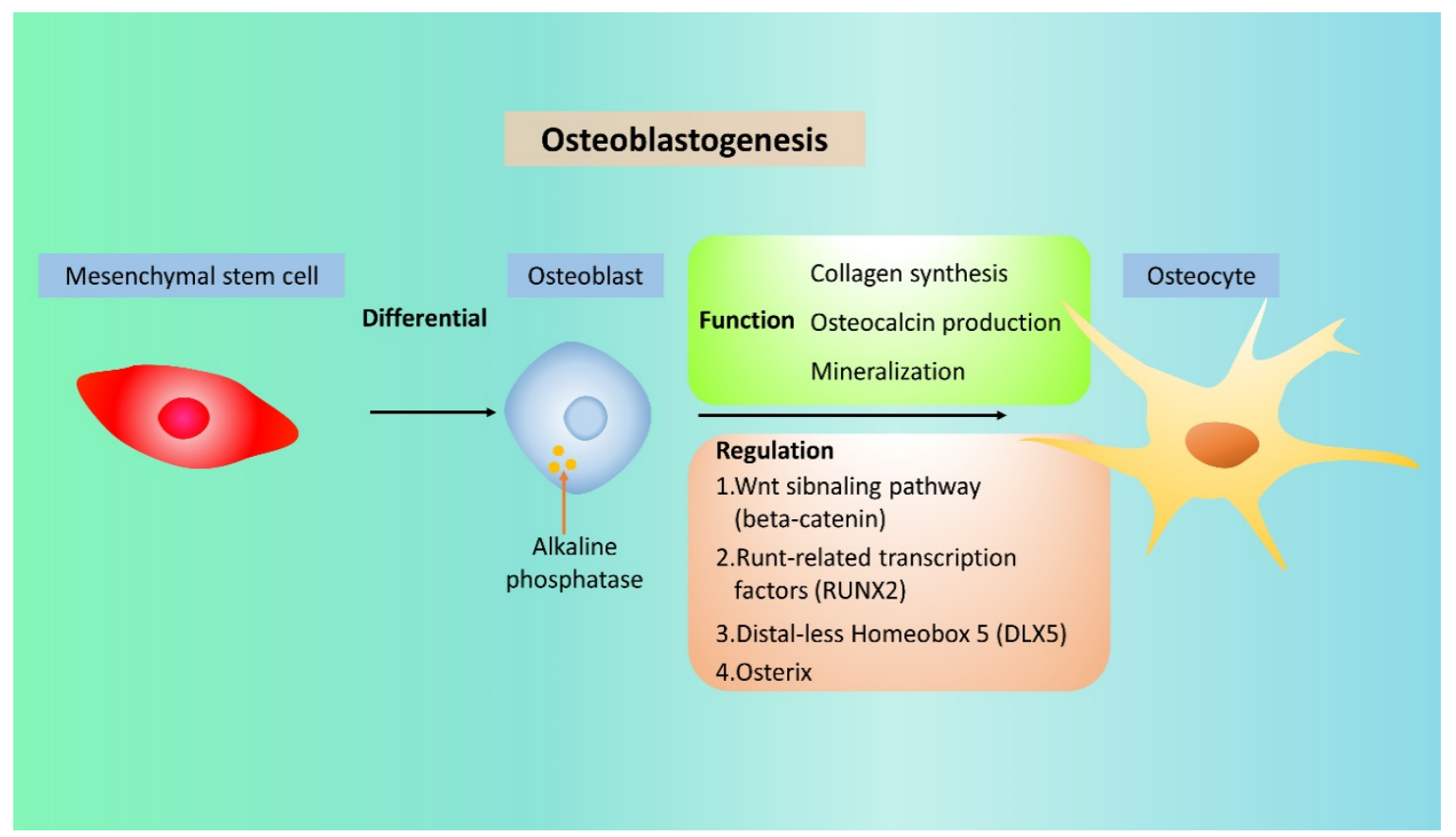

Figure 2. The differentiation and regulation in the osteoblastogenesis process. In the osteoblastogenesis, osteocytes are derived from mesenchymal stem cell then osteoblast which regulated by beta-catenin, Runt-related transcription factor 2 (RUNX2), Distal-Less Homeobox 5 (DLX5), and osterix. The collagen synthesis, osteocalcin production, and mineralization let the osteoblasts formulate the osteocytes.

Bone remodeling is a continuous balance between bone absorption and bone formation [37]. Osteocytes serve as the main regulators of bone homeostasis between OCs and OBs [38]. In the bone, osteocytes detect microcracks, mechanical strains, and alternations in the hormonal milieu, and respond these changes by bone remodeling $[39,40]$. They control the activity of OCs and OBs by secreting the regulators of these cells, such as RANKL, OPG, and sclerostin [41,42]. Through these responses, osteocytes play a key role in bone homeostasis.

\section{Myeloma Induced Bone Disease}

In myeloma patients, the disrupted OB-OC-osteocyte axis leads to unbalanced bone remodeling with a dramatic change in osteolytic bone lesions [43,44]. Dysregulation of OCs and OBs is the key mechanism of myeloma bone lesions, in particular, the upregulation of osteoclastogenesis, inhibition of OB activity, and increase in apoptosis of osteocytes $[36,45,46]$. In turn, the growth factors released by the increased bone resorption process regulate the survival, proliferation, and drug resistance of myeloma cells, creating a vicious cycle of myeloma expansion and myeloma bone lesions [46,47]. Since the pathogenesis of MBDs is primarily caused by generalized activated OC activity, there is a relationship among tumor burden, disease activity, OC numbers, and resorption status in myeloma patients.

There are many signaling factors in MM patients that promote OC differentiation and activity, such as RANKL, chemokines (CCL3), IL-6, and myeloma-derived exosomes [48,49]. These signaling factors promote and stimulate the migration, survival, and differentiation of OC precursor cells [50,51]. Additionally, myeloma cells modify the surrounding microenvironment and inhibit osteogenesis by direct secretion of Wnt antagonists, such as DKK-1, and by inducing the OB inhibitors, sclerostin, and activin, from mesenchymal cells and osteocytes [35,37]. Osteocytes play a role in myeloma bone lesions as the number of osteocytes is reduced in myeloma patients [52,53] as a result of apoptosis in myeloma disease. The apoptotic osteocytes express high levels of RANKL and sclerostin, which further inhibits OB differentiation and attracts OC precursors. The adherence of myeloma cells to BMSCs by binding to vascular cell adhesion molecule-1 (VCAM-1) also stimulates the release of 
many factors that regulate osteoclastogenesis and osteoblastogenesis [14,46]. These factors include macrophage-colony stimulating factor (M-GCSF), IL-1, IL3, IL6, IL17, and macrophage inflammatory protein 1 (MIP-1-alpha/CCL3), TNF-alpha and beta, parathyroid hormone-related protein (PTHrP), and vascular endothelial growth factor (VEGF). The myeloma and the microenvironment orchestrate these factors and increase the RANKL/OPG ratio in the development of osteolytic bone lesions in myeloma [30].

\section{The RANK/RANKL Pathway}

The RANK/RANKL pathway is the most relevant physiological and therapeutic signaling pathway for the bone resorption regulation [51]. RANK, a subgroup of the tumor necrosis factor (TNF) family, is a transmembrane signal receptor that is mainly expressed on the surface of OCs [53]. RANK ligand (RANKL) is the associated cytokine in the microenvironment that interacts with RANK for bone resorption and is mainly secreted by osteocytes, and to a lesser extent, by BMSCs and OBs. Through the binding of RANKL to RANK on immature OCs, RANKL induces the differentiation of OCs into mature OCs, which are the main regulator of osteoclastogenesis [54]. Upon the binding of RANKL to its receptor RANK, several signaling pathways for osteoclastogenesis are triggered, including the expression of nuclear-factor-activated T-cell cytoplasmic 1 (NFATc1) [55-57]. NFATc1 is the master regulator of OC differentiation that particulates in many pathways; the activation also triggers NF- $\mathrm{KB}$ and mitogen-activated protein kinase (MAPK) and subsequent pathways, including INK, p38, ERK, and Src [57,58]. It promotes the expression of OC-specific genes, including tarftrate-resistant acid phosphatase (TRAP), OC stimulatory transmembrane protein (OC-STAMP), cathepisn K, and MMP9, which induce bone resorption. RANKL also triggers the expression of c-Fos, a major component of the activator protein-1 transcription factor complex, which induces the expression of NFATc1 [59,60] (Figure 3).

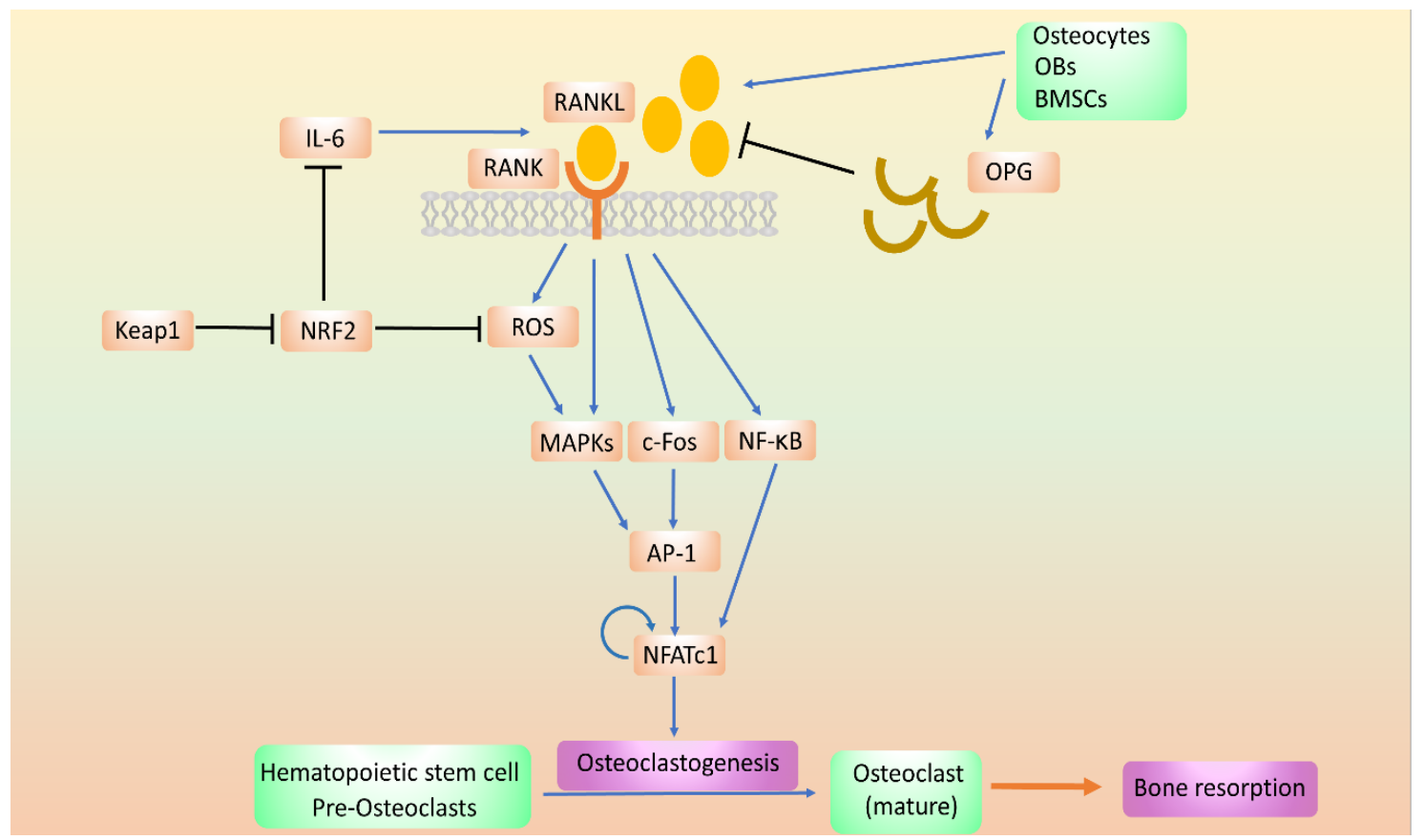

Figure 3. The regulation of signal pathways in osteoclastogenesis. In osteoclast (OC) differentiation, the RANKL/RANK pathway that regulate the downstream intracellular markers such as mitogen-activated protein kinases (MAPKs), c-Fos, and NF- $k B$, which contribute the OC maturation. In the pathway, NRF2 could reduce the osteoclastogenesis by ROS inhibition.

In contrast to RANKL, osteoprotegerin (OPG), a decoy receptor of the TNF family, is secreted by OBs and acts as a RANK antagonist by binding to RANKL, which inhibits osteoclastogenesis [61]. An increase 
in the RANKL/OPG ratio was noted in both inflammatory diseases and several cancers, which resulted in the loss of bone mass [62]. An imbalance in the ratio was also found in myeloma patients with increased RANKL expression and a decrease in OPG expression in the marrow environment, which shows that the ratio of RANKL/OPG plays a critical role in bone metabolism in myeloma.

In myeloma status, the plasma cell increases RANKL expression by direct secretion and by myeloma stromal cells through direct cell-to-cell contact and by osteocytes [63]. On the other hand, myeloma cells decrease OPG levels by reducing the secretion of OPG from OBs and stromal cells. In addition, upregulation of cytokines, such as IL-1, IL6, TNF- $\alpha$, and hormones, such as PTHrp, increases RANKL expression and decreases OPG levels through the contact of plasma cells and stromal cells, and the myeloma microenvironment [64]. In particular, myeloma cells induce osteocyte apoptosis by activation of the NOTCH pathway, and the apoptosis process of osteocytes induces high levels of RANKL $[65,66]$.

\section{Introduction of NRF2 (or Structure, Function, and Regulation of NRF2)}

Nuclear factor erythroid 2-related factor 2 (NRF2) is a transcription factor in numerous cell types [67]. It belongs to a basic leucine zipper protein family (bZIP), which is comprised of 4 members, including NRF1, NRF2, NRF3, and P45 NF-E2 [68]. In these bZIP transcription factors, NRF1 and NRF2 are ubiquitously distributed, the expression of NRF3 is restricted to the liver and placenta, and the expression of NF-E2 is limited to erythrocytes [69]. NFR2 is considered as the main mediator of cellular adaptation to redox stress among these members [70,71]. From its protein conformation of N- to C-terminus, NRF2 has seven functional domains, arranged as NRF2-ECH homology (Neh) domain 2 (Neh2), Neh4, Neh5, Neh7, Neh6, Neh1, and Neh3 [72-74]. Neh2 domain contains specific sequences for binding with the negative regulators Keap1 that mediate the degradation of NRF2. The Neh4 and Neh5 form the transactivation domain of NRF2 that recruits CREB-binding protein (CBP) and receptor-associated coactivator 3 (RAC 3). Neh7 domain interacts with retinoid X receptor alpha $(R X R \alpha)$, which represses the transactivation activity of NRF2. Neh6 domain contains two conserved redox-independent degrons known as DSGIS and DSAPGS motifs, which can be recognized and phosphorylated by glycogen synthase kinase- $3 \beta$ (GSK-3 $\beta$ ), then targeted for degradation by $\beta$-transducin repeat-containing protein ( $\beta$-TrCP) E3 ubiquitin ligase. Neh1 is a CNC (cap ' $n$ ' collar)-basic leucine zipper domain that mediates binding to DNA and dimerizing with small musculoaponeurotic fibrosarcoma (sMaf) proteins. The C-terminal Neh3 domain interacts with the chromo-ATPase/helicase DNA-binding protein 6 (CHD6) is important for the transcriptional activity of NRF2.

NRF2 is a master regulator to maintain cellular redox homeostasis and regulates the expression of a large cytoprotective network, which include enzymes involved in the biosynthesis, utilization, and regeneration of nicotinamide adenine dinucleotide phosphate (NADPH), thioredoxin, and reduced glutathione (GSH). In addition, detoxification enzymes, such as glutathione S-transferase (GST), aldo-keto reductases, and $\mathrm{NAD}(\mathrm{P}) \mathrm{H}$ : Quinone osidoreductase 1 (NQO1) as well as the proteins participate the recognition and clearance of damaged proteins and organelles, such as proteasomal subunits and autophage-related proteins [70,75-77]. The main functions of the products of NRF2-related genes are to neutralize electrophiles and reactive oxygen/nitrogen species (ROS/RNS), thus reduce intracellular oxidative stress that protect the cell from harmful insults of these agents [77,78]. NRF2 is also involved in the regulation of a number of metabolic genes, such as the biosynthesis of purine nucleotides, the pentose phosphate pathway, and enhancement of mitochondrial function and fatty acid metabolism [79].

As one of the master regulator factors of cytoprotective functions, NRF2 is regulated mainly by the level of protein stability. At homeostasis, the level of NRF2 is low as a result of continuous ubiquitination and proteasomal degradation. However, under stress the NRF2 is able to accumulate eventually allowing it to bind with sMaf in the nucleus and initiate the transcription of its target.

KEAP1, a cytoplasmic actin-binding protein, tethers NRF2 in the cytoplasm and represses the activity of NRF2. In addition to being a repressor of NRF2 activation, KEAP1 serves as the 
intracellular sensor of electrophiles and oxidants, which induce stabilization and activation of NRF2. When exposed to either electrophiles or oxidants, KEAP1 is modified on its cysteine residues, leading to the release of NRF2 from KEAP1. This action subsequently leads to the translocation of NRF2 in the nucleus. Upon translocation into the nucleus, activated NRF2 forms heterodimers with sMaf proteins, and dimerization is necessary for DNA binding [80,81]. The NRF2-sMaf then binds to the regulatory area of antioxidant response elements (ARE), a cis-acting enhancer sequence located in the promoter regions of genes encoding for antioxidants and detoxifying enzymes [82], such as GSTs, NADPH-quinone oxidoreductase (NQO) 1, and glutamate-cysteine ligase catalytic (GCLC) subunit $[83,84]$. ARE comprises the core sequence $5^{\prime}-$ TGACnnnGC-3', which is critical for binding.

There are three ubiquitin ligase systems that are implicated in the NRF2 degradation. KEAP1 is the main negative regulator of NRF2 activity. Under homeostasis, NRF2 interacts with its cytosolic repressor, KEAP1, a subunit of the Cullin 3-RING Box 1 (CUL3-RBX1) E3 ubiquitin ligase complex that primes NRF2 for proximal degradation $[85,86]$. The second ubiquitin ligase system is mediated by $\beta$-TrCP-Cullin 1-RING Box 1 (CUL1-RBX1) E3 ubiquitin ligase complex in a KEAP1-independent manner. Nuclear NRF2 can be targeted and phosphorylated by GSK-3 $\beta$ in Neh6 domain, which creates a degradation domain that is then recognized by $\beta$-TrCP and tagged for proteasome degradation by a CUL1-RBX1 E3 complex $[87,88]$. In line with the finding, genetical or pharmacological inhibition of GSK-3 $\beta$ results in an increase in NRF2 protein levels. GSK-3 $\beta$ inhibition-mediated NRF2 stabilization occurred in embryonic fibroblast from KEAP-knockout mice and in cell ectopically expressed NRF2 $\triangle E T G E$ mutant which cannot bind to KEAP1, further demonstrated that GSK-3 $\beta$ degrades NRF2 in a KEAP1-independent manner $[88,89]$. The third pathway controlling NRF2 stability has been reported in cirrhotic levers with the protein HRD1, an E3 ubiquitin ligase associated with the ER membranes. HRD1 is transcriptionally induced by ER stress; HRD then interacts with the Neh4-5 domains of NRF2 and promote its ubiquitination and degradation [73].

Autophagy is generally believed to degrade long-lasting, misfolded proteins, and damaged organelles via lysosomal pathway. Autophagy was found to be directly linked to NRF2 through an adaptor protein sequestosome 1 (SQSTM1)/p62 [90]. A KEAP1 interacting region (KIR) in p62 binds to KEAP1 in the same basic domain as NRF2, therefore competes with NRF2 for binding to KEAP1 and leads to NRF2 accumulation and subsequent transcriptional activation of its target genes [90]. In addition, upon binding to KEAP1, p62 can induce autophagic degradation of KEAP1. Interestingly, p62 can be induced under oxidative stress condition in an NRF2-dependent manner, thus creating a positive feedback loop between NRF2 and p62 [91].

\section{The Role of NRF2 in the Myeloma Microenvironment}

$\mathrm{MM}$ is the result of neoplastic transformation from a terminally differentiated B lymphocyte. As such, it primarily exists and proliferates in the bone marrow similar to other normal plasma cells [92-94]. The interaction of plasma cells with the surrounding bone marrow environment functionally and physically is important for the proliferation and survival of plasma cells [95]. Two compartments in the bone marrow microenvironment interact with plasma cells, which promote proliferation, survival, and even drug-resistance of myeloma cells [92-94]. One is the cellular part comprising hematopoietic cells and non-hematopoietic cells, such as fibroblasts, OBs, mesenchymal stem cells, myeloid-derived suppressor cells (MDSCs), and BMSCs. Soluble factors, such as cytokines, chemokines, growth factors, and extracellular matrix proteins, comprise the non-cellular part that also interact with myeloma cells.

For the soluble factors, IL-6 is one of the most critical factors for myeloma cell survival, proliferation, and drug resistance [96,97]. In the marrow milieu, many cells including MDSCs, fibroblasts, macrophages, adipocytes, and dendritic cells, secrete IL-6. IL-6 has been shown to increase RANKL protein expression in murine osteoblasts and BMSCs, and been considered as a bone resorption cytokine [98]. Elevated IL-6 can be attributed to the activation of NF- $\mathrm{kB}$ signaling in many cell types [99]. Suppression of NRF2 and activation of NF- KB were observed in pathological conditions, such as 
inflammation [100]. NRF2 competes with NF-KB for downstream signaling, such as with co-activator $\mathrm{CBP} / \mathrm{p} 300$, and the activated NRF2-suppressed NF-kB signaling [101]. Therefore, the expression of NRF2 is associated with a decrease in IL-6 expression in several cell types [102]. In NRF2-deficient mice, macrophages and embryonic fibroblasts showed higher expression of NF- $\mathrm{kB}$ and production of inflammatory cytokines IL-6 [103,104].

Additionally, vascular cell adhesion molecule-1 (VCAM-1) is also a target of NF- $\mathrm{kB}$. As such, the suppression of NF- $\mathrm{KB}$ signaling in BMSCs results in decreased expression of ICAM-1 and VCAM-1, which affects the resistance of MM to proteasome inhibitors [105,106]. Likewise, activation of NRF2 could suppress the adhesion molecules expression in BMSCs by acting as an antagonist of the NF- $\mathrm{KB}$ pathway [106]. Activation of NRF2 by curcumin and dimethyl fumarate inhibits the expression of NF- $\mathrm{KB}$ and adhesion molecules in animal models [107]. These findings suggested that NRF2, through inhibiting the transcription activity of NF- $\mathrm{kB}$, could suppress both the soluble factor (e.g., IL-6)-mediated drug resistance and cell-adhesion-mediated drug resistance. [15,108]. Given the critical role of IL-6 plays in RANKL expression, the effect of NRF2 on RANKL expression/secretion in the bone marrow microenvironment is worth pursuing.

\section{The Role of NRF2 in Bone Metabolism}

Since oxidative stress affects bone homeostasis, it is reasonable to suppose that the NRF2 signaling pathway plays a role in bone metabolism $[109,110]$. ROS originates from aging, hormone imbalance, and insults from radiation and trauma as well as cancers has adverse effects on bone structure and lead to bone fragility $[14,46]$. In contrast, antioxidant defenses significantly decrease the osteoporotic status of postmenopausal women. This stresses the important role of the balance between oxidants and antioxidants in the maintenance of bone metabolism between OCs and OBs. As a master regulator of antioxidant response system in the body, and defect of NRF2 leads to a deficiency in the production of numerous antioxidant enzymes and glutathione and an increase in intracellular ROS levels in both OC and OB precursor cells $[74,109,111]$. The increase in osteoclastogenesis and decrease in osteoblastogenesis has been noted to be associated with an imbalance between the plasma antioxidant and oxidant biomarkers in postmenopausal osteoporotic women [111]. These findings highlight the role of oxidative stress in bone metabolism.

In animal studies, deletion of NRF2 in bone leads to a lower mineral density, and the bone strength of vertebral and femurs bodies was significantly lower than that in normal control group [112]. The lower bone mass and bone strength in NRF2-deficient mice were resulted from the imbalance of bone formation and resorption [113] specifically in relation to bone remodeling, which includes co-ordination of OC and OB cells continuously and/or sequentially [114]. The remodeling of bone caused by the imbalance of OC and OB activity induces the removal and restoration of bone tissues [109]. These studies suggest NRF2 partakes in a critical role in bone metabolism.

\section{The Effects of NRF2 on OC}

OCs are multinucleated cells derived from hematopoietic stem cells. Accumulation of osteoclastogenesis results in bone destruction of bone lesions in inflammatory disease and malignant status $[115,116]$. RANK/RANKL is the key inducer of OC differentiation and control of osteoclastogenesis [54]. Produced by OB and fibroblast cells, RANKL is expressed in the destructive stage of rheumatoid arthritis with an increase in osteoclastogenesis [116]. In cell line studies, expression of RANKL decreased the ratio of NRF2/KEAP1, which decreased the expression of NRF2-related enzymes and favored the increase in ROS activity $[117,118]$. ROS is a downstream molecular signal of RANKL and is associated with OC differentiation [119]. Since a reduction of ROS inhibits OC activity and osteoclastogenesis, a depletion of NRF2 will result in an elevated level of intracellular ROS from the removal of the antioxidant suppressing ability of NRF2 therefore leading to an increase in the quantity of OCs and osteoclastogenesis [120]. Moreover, overexpression of NRF2 directly or by inhibition of KEAP1 decreases the expression of RANKL, which agreed with the notion that 
NRF2-deficient induced osteoclastogenesis could result from elevated RANKL expression in bone marrow microenvironment $[112,119,121]$. In addition, NRF2 could influence osteoclastogenesis by the expression of IL-6 [122]. These data suggested that NRF2 is crucial to OC activity, but the underlying mechanism of NRF2 in regulating OC activity remains unclear [123]. Increased p38 MAP kinase activity but not the NF-kB pathway was associated to ROS elevation in NFR2 knockout mice [124-127]. Moreover, NRF2 also represses OC activity via regulating the activity of NFATc1, which is the master transcription factor for osteoclastogenesis $[124,128]$. Despite of these findings suggesting a suppressive role of NRF2 in osteoclastogenesis and OC activity, it is still not clear whether the same effects of NRF2 can be observed in MBD. It has been shown that the levels of oxidative stress biomarkers were significantly higher in MM patients with bone lesions compared with those without lytic bone lesions [129]. Moreover, RANKL is the major regulator of pathological bone remodeling in MBD. Thus, it is important to compare the ROS level and NRF2 activity in OCs in MM patients with and without bone lesions, and in MBD mouse model.

\section{The Role of NRF2 in OB}

The relationship of NRF2 in the activity and differentiation of OBs remains controversial [109]. The NRF2 knockout mice study reported by Sun and colleagues showed lower bone mass not only from increased bone resorption but also from reduced bone formation with a lower mineral apposition rate [112]. These data support that NRF2-deficient OBs lose their ability to differentiate and mineralize, which decreases bone formation with reduced bone mass.

The role of NRF2 in regards to OBs may also be related to the level of intracellular ROS, as a higher level of ROS has been observed in NRF2 deficient OBs and stromal cells. This increased level of oxidative stress from elevated ROS levels results in the inhibition of OB differentiation [121]. NRF2 levels in OBs also interact with osteoclastogenesis because a decrease in ROS levels by NRF2 activation leads to a reduction in RANKL, which inhibits OC activity and osteoclastogenesis [121]. NRF2 activation also reduced IL-6 secretion, leading to suppression of osteoclastogenesis [122]. Therefore, it is presumed that the activated NRF2 could promote osteoblastogenesis and suppress osteoclastogenesis.

However, overexpression of NRF2 caused deleterious effects on OBs since overexpression of NRF2 inhibits RUNX2 in OB cells $[130,131]$. This inhibition of RUNX2 presents a problem as it is a master transcription factor that regularize embryonic bone development and postnatal $\mathrm{OB}$ functions $[132,133]$. RUNX2 deficiency causes suppression of endochondral and intramembranous bone formation and arrest of chondrocyte maturation [134]. Although, RUNX2 levels should be kept in an ideal range since both RUNX2-deficient mice and animals with RUNX2 overexpression presented with osteopenia $[135,136]$. This implies that many transcription factors in bone acquired a narrow expression range for physical functions [135]. These data suggest that the role of NRF2 in OBs, such as those in regards to RUNX2, is complicated and depends on many factors, such as age, sex, and physiological versus pathological conditions, and an optimal range for bone formation $[109,135]$. Which further demonstrates the important role that NRF2 has in the mechanism for bone formation.

\section{The Role of NRF2 in Mitochondrial Regulation of Bone Homeostasis}

In addition to the regulation of proteins involved in oxidative response and xenobiotic detoxification and the inhibition of inflammation, recent evidence indicated that NRF2 also affects mitochondrial functions $[137,138]$. As a center where multiple redox reactions take place, mitochondria are the principal source of ROS. By transcriptional regulating of several antioxidant proteins, NRF2 maintains the redox homeostasis of mitochondria. Antioxidant enzymes involving in GSH biosynthesis including $\gamma$-glutamyl cysteine ligase catalytic (GCLC) and modulatory (GCLM) subunits as well as glutathione reductase (GR) are induced by NRF2 and participates in the maintenance of the mitochondrial GSH pool [139]. NRF2 also activates the expression of glucose-6-phosphate dehydrogenase (G6PD) and 6-phosphogluconate dehydrogenase (6PGD) which are key enzymes in the pentosephosphate pathway (PPP). One important function of PPP is producing NADPH, a cofactor 
that is required for the generation of reduced GSH [140]. Furthermore, mitochondrial antioxidant enzymes such as superoxide dismutase 2 (SOD2), GSH peroxidases 1 (GPx1), thioredoxin reductase 2 (TRXR2), peroxiredoxin 3 (PRDX3), and PRDX5 have been shown to be upregulated in NRF2 dependent manner [138].

NRF2 also participates in mitochondrial biogenesis and oxidative phosphorylation (OXPHOS). Which along with Nuclear respiratory factor-1 (NRF-1) and mitochondrial transcription factor A (TFAM) are central factors in controlling mitochondrial biogenesis [141]. Piantadosi et al. demonstrated that in cardiomyocytes activates NRF2 upregulates NRF-1 and subsequently activates mitochondrial biogenesis genes [142]. Additionally, evidence provided by Wu et al. indicated activated NRF2 binds to the promoter of TFAM and enhances mitochondrial biogenesis [143]. In addition to mitochondrial biogenesis, NRF2 has also been shown to modulate mitochondrial function directly [144]. Holmström et al. showed that cells and mitochondria isolated from NRF2-knockout mice displayed lower levels of respiration and ATP production. Conversely, those processes were increased in mice counterparts with genetically activated NRF2 (KEAP1-knockout or KEAP1-knockdown) [145]. In addition, the reduction of respiration and ATP levels in NRF2 deficiency condition could be a result of the limitation of substrate. Fatty acid oxidation (FAO) produces acetyl-CoA which fuels the TCA cycle, and then enhances the generation of $\mathrm{FADH}_{2}$, and $\mathrm{NADH}$, which are major electron donors in OXPHOS. Interestingly, FAO capacity was reduced in cells and mitochondria isolated from NRF2-knockout mice [146]. Moreover, NRF2 depletion diminished the expression of carnitine palmitoyltransferase $(\mathrm{CPT})$, a rate-limiting enzyme in FAO, while pharmacological activation of NRF2 increased Cpt1a gene expression [147,148].

As mitochondria plays vital roles in multiple cellular functions such as bioenergetics, biosynthesis, and apoptosis, dysfunctions in the mitochondrial quality control system are associated with the pathogenesis of several disease including metabolic diseases, cancers, and neurodegenerative disease $[138,149]$. Damaged mitochondria can be removed by mitophagy, a process consisting of selective sequestration of excessive or damaged mitochondria by the autophagosome and subsequent degradation by lysosome [150]. PTEN-induced kinase 1 (PINK1) and p62 are crucial players in mitophagy. Similarly to p62, the expression of PINK1 can be induced by oxidative stress in NRF2-dependent manner. Moreover, the increased PINK1 reduces oxidative stress-induced cytotoxicity by removing damaged mitochondria [151]. These findings suggested a potential role of Nrf2 in further controlling mitochondrial integrity via regulating the expression of p62 and PINK1.

Recently, multiple lines of evidence revealed that mitochondria plays pivotal roles in regulating the homeostasis of stem cells particularly in the context of bones [152]. As bone remodeling persists throughout life, the lineage commitments and dynamic interactions of two important stem cell populations-hematopoietic stem cells (HSCs) and mesenchymal stem cells (MSCs) - must be tightly regulated and finely tuned. Mitochondrial compromise has been shown to be closely associated with the pathogenesis of stem cell dysfunction in bone aging and pathologies [152]. It is understood that the fates of stem cells are influenced by metabolic status-glycolysis and OXPHOS [153]. In the skeletal system, the OBs differentiation from MSCs is mainly dependent on this metabolic switch. MSCs/osteogenic progenitors mostly rely on glycolysis, whereas mature OBs acquired energy by OXPHOS [154]. Significant upregulation of oxygen consumption rate and intracellular ATP level during osteoblastogenesis have been evidenced, indicating the involvement of mitochondrial energy metabolic switch in lineage commitment of MSCs. On the other hand, compromising of mitochondrial OXPHOS in MSCs by treatment with electron transport chain (ETC) inhibitor (e.g., antimycin A), uncoupler (e.g., FCCP), or ATP synthase inhibitor (e.g., oligomycin) leading to the suppression of osteoblastogenesis $[155,156]$. It is worthy of note that metabolic switch to OXPHOS could result in elevated presence of reactive oxidative species (ROS) as a byproduct, while concomitantly, differentiated OBs activate an antioxidant defense system, in particular SOD2, to prevent endogenous ROS accumulation [155]. SOD2 deficiency causes oxidative damage, impairs osteogenic differentiation and leads to the development of osteoporosis [156,157]. In addition, morphological alterations of 
mitochondria such as enlargement, elongation, and activation-related network formation are prominent features during osteoblastogenesis. As aforementioned, activation of TFAM, a transactivation target of NRF2, is crucial for mitochondrial functions, indicating the involvement of NRF2 in regulating mitochondria function and osteoblastogenesis. Moreover, activation of NRF2 activity with natural products ameliorate osteoporosis in rats $[158,159]$. These findings further support the notion that NRF2, the master regulator of antioxidant defense system, is crucial and positively associates with osteoblastogenesis.

HSCs, another major stem cell population in bone, participates in bone remodeling by differentiating into OCs. Similar to osteoblastogenesis, OC differentiation is accompanied by remarkable mitochondria increase and upregulation of mitochondrial metabolism [160]. Impairment of mitochondrial respiration by knocking out of mitochondrial complex I subunit Ndufs4 inhibits osteoclastogenesis and leads to osteopetrosis [161]. However, in contrast to osteoblastogenesis, knockdown of SOD2 both in vitro and in vivo increases mitochondrial ROS production and leads to accelerated osteoclastogenesis and reduction of bone volume [162]. Accumulating evidence supports that ROS are essential regulators of OCs lineage commitment from HSCs [102,163]. In the light of these findings, NRF2 clearly regulates mitochondrial function and ROS production in a sophisticated manner during osteoclastogenesis. Furthermore, NRF2 might also promote HSC lineage allocation toward OCs through regulating mitochondria biogenesis and mitochondrial quality, while restrain OCs from hyper-activation by fine-tuning ROS production.

\section{The Role of NRF2 in Mitochondrial Regulation in Myeloma}

As discussed in our previous report, NRF2 plays opposite roles in normal and cancer cells. Upregulation of NRF2 target genes were observed in chemoresistant and relapsed/refractory MM patients [108]. NRF2 activation has also been reported to contribute to proteasome inhibitors resistance in MM [15]. Increased NRF2 activity, which activates pro-survival signaling pathways, was observed in primary $\mathrm{MM}$ and $\mathrm{MM}$ cell lines treated with proteasome inhibitors. In line with the findings, genetic and pharmacologic inhibition of NRF2 reestablished the sensitivity of MM cells to bortezomib and carfilzomib $[108,164]$. In addition to drug resistance, NRF2 could affect MM cell growth and survival, as NRF2 inhibitors suppress MM cell growth and reduce the viability of MM cells $[165,166]$.

Notably, elevated protein expression of NRF2 in carfilzomib-resistant MM cells was accompanied by increased level/expression of p62 and FAO [108]. These findings indicated that NRF2 could enhance mitochondrial function and quality in MM cells. Moreover, the expression of SOD2, mitochondria membrane potential, oxygen consumption rate, and ATP production were higher in bortezomib-resistant MM cells [167]. Recently, Zhan et al. demonstrated that gene expression of mitochondrial biogenesis signatures were significantly higher in relapsed and drug resistant myeloma samples than newly diagnosed patient samples. Inhibition of mitochondria OXPHOS dramatically reduced the growth of MM xenograft in in vivo model [168]. Similar results were reported by Alejandra Ortiz-Ruiz and colleagues [169]. These findings further demonstrated a pivotal role of mitochondria in drug-resistance of MM cells. Together, we reasoned that NRF2 could be involved with drug resistance through enhancing anti-oxidant and detoxification responses, and promoting mitochondria functions.

\section{Concluding Remarks and Future Perspectives}

Osteolytic bone lesions are one of the central features of MM, which leads to morbidity of patients. MBDs are caused by many factors from myeloma cells and the microenvironment that stimulate OCs to resorb bone and inhibit $\mathrm{OB}$ activity to increase bone mass. The dysfunction of the $\mathrm{OC} / \mathrm{OB}$ axis in myeloma patients results in osteolytic lesions and/or osteoporosis, leading to bone pain, fracture, diminished bone survival, and reduced quality of life in patients. Many signaling pathways and factors were noted to be associated with MBDs. The role of the RANKL/OPG pathway was found to participate in MBD, and the identification of the RANKL/OPG pathway also led to the development of RANKL inhibitors for myeloma bone lesion therapy. 
NRF2, a master regulator of cellular defense system, has been considered as a target for chemoprevention and for cancer therapy. Here, we proposed that NRF2 can also be a therapeutic target for treating MBD. As mentioned, the balance of OCs and OBs is impaired in osteolytic bone lesions, where $\mathrm{OB}$ activity is suppressed while the osteoclastogenesis is strongly upregulated. Activation of NRF2 holds the potential for reversing the unbalance of OCs and OBs, since NRF2 could promotes osteoblastogenesis, while restrain uncontrolled osteoclastogenesis (Figure 4). Thus NRF2 activators should prove to be beneficial for MM patients with osteolytic lesions. However, as we have discussed above, NRF2 activation could have the opposite effect in BM environment cells and in MM cells. Thus, the effect of NRF2 activators on the growth and drug resistance of MM cells should be carefully noted. Nonetheless, the fact that cancer cells can activate NRF2 through several mechanisms including somatic mutations in Keap1 or NRF2 gene loci, hypermethylation at the promoter region of Keap1, transcriptional upregulation of the NRF2 gene through oncogene-dependent signaling, interruption of Keap1-NRF2 interaction, and the modification of Keap1 protein by electrophilic oncometabolites, may provide a possible resolution for this contradiction, in which cancer cells could lose their sensitivity to NRF2 activators $[170,171]$. In line with this notion, we have found that cells which expressed higher basal NRF2 protein level also have a weaker response to NRF2 activators. Therefore, it is worthy of further investigation for the effects of NRF2 activators on MBD in models with proteasome inhibitor-resistant MM cells or NRF2 hyperactivated MM cells. Owing to the elusive and complex nature of MM, more research is warranted to further investigate the specific role of NRF2 in myeloma bone lesions and to identify novel agents for NRF2 therapy. Nevertheless, for future clinical practice, we would propose that a test to profile the status of NRF2 signaling and/or the mutation in NRF2 signaling genes in MM cells collected from patient could be helpful to identify eligible population for NRF2 activator therapy for MBD. Furthermore, it is also possible that different classes of NRF2 activator should be used to treat MBD that were induced by MM cells with different NRF2 activation mechanisms.



Figure 4. The role of NRF2 in mitochondrial regulation of bone homeostasis in MBD. The balance of OCs and OBs is impaired in osteolytic bone lesions, where OB activity is suppressed while the osteoclastogenesis is strongly upregulated. Activation of NRF2 could promote osteoblastogenesis, while restraining uncontrolled osteoclastogenesis. Red arrows indicate active effect; Blue bar arrow indicates suppressive effect. 
Author Contributions: Writing-original draft preparation, H.-H.H.; writing-review and editing, C.-H.Y., C.-M.H., S.Y.H.; visualization, C.-M.H.; supervision, C.-H.Y., C.-M.H., S.Y.H.; H.-H.H.; project administration, H.-H.H. All authors have read and agreed to the published version of the manuscript.

Funding: This study was supported by a grant from the Kaohsiung Medical University Hospital (KMUH108-8R24).

Conflicts of Interest: The authors declare no conflict of interest.

\section{Abbreviations}

\begin{tabular}{|c|c|}
\hline ARE & antioxidant response elements \\
\hline bZIP & basic leucine zipper protein family \\
\hline$\beta-\operatorname{TrCP}$ & $\beta$-transducin repeat-containing protein \\
\hline BMSCs & bone marrow stromal cells \\
\hline CCL3 & chemokine $\mathrm{C}-\mathrm{C}$ motif 3 \\
\hline CBP & CREB-binding protein \\
\hline CUL1-RBX1 & Cullin 1-RING Box 1 \\
\hline CUL3-RBX1 & Cullin 3-RING Box 1 \\
\hline DDK-1 & dickkopf-1 \\
\hline DLX5 & Distal-Less Homeobox 5 \\
\hline GCLC & glutamate-cysteine ligase catalytic \\
\hline GSH & glutathione \\
\hline GSTs & glutathione S-transferases \\
\hline HSCs & Hematopoietic stem cells \\
\hline IL-1,6 & Interleukin-1,6 \\
\hline MIP-1-alpha & macrophage inflammatory protein 1 \\
\hline M-GCSF & macrophage-colony stimulating factor \\
\hline MAPK & mitogen-activated protein kinase \\
\hline MM & Multiple myeloma \\
\hline Maf & Musculoaponeurotic fibrosarcoma \\
\hline MDSCs & myeloid-derived suppressor cells \\
\hline MBD & Myeloma bone disease \\
\hline MSCs & Mesenchymal stem cells \\
\hline NQO & NADPH-quinone oxidoreductase \\
\hline RANKL & NF-kappa B ligand \\
\hline NADPH & nicotinamide adenine dinucleotide phosphate \\
\hline NFATc1 & nuclear-factor-activated T-cell cytoplasmic 1 \\
\hline NRF2 & Nuclear factor erythroid 2-related factor 2 \\
\hline OC-STAMP & osteoclast stimulatory transmembrance protein \\
\hline OB & Osteoblast \\
\hline $\mathrm{OC}$ & Osteoclast \\
\hline OPG & Osteoprotegerin \\
\hline OXPHOS & oxidative phosphorylation \\
\hline PTHrP & parathyroid hormone-related protein \\
\hline PTH & Parathyroid hormone \\
\hline NQO1 & NAD(P)H: quinone osidoreductase 1 \\
\hline RANKL & RANK ligand \\
\hline ROS & reactive oxygen species \\
\hline $\mathrm{RXR} \alpha$ & retinoid $X$ receptor alpha \\
\hline RUNX2 & Runt-related transcription factor 2 \\
\hline TRAP & tartrate-resistant acid phosphatase \\
\hline TGF-beta & transforming growth factor beta \\
\hline TNF-alpha & tumor necrosis factor-alpha \\
\hline VCAM-1 & vascular cell adhesion molecule- 1 \\
\hline VEGF & vascular endothelial growth factor \\
\hline
\end{tabular}




\section{References}

1. Moreau, P.; San Miguel, J.; Sonneveld, P.; Mateos, M.V.; Zamagni, E.; Avet-Loiseau, H.; Hajek, R.; Dimopoulos, M.A.; Ludwig, H. Multiple myeloma: ESMO Clinical Practice Guidelines for diagnosis, treatment and follow-up. Ann. Oncol 2017, 28, iv52-iv61. [CrossRef] [PubMed]

2. Rajkumar, S.V.; Kumar, S. Multiple Myeloma: Diagnosis and Treatment. Mayo Clin. Proc. 2016, 91, $101-119$. [CrossRef] [PubMed]

3. Chappard, D.; Bouvard, B.; Basle, M.F.; Legrand, E.; Audran, M. Bone metastasis: Histological changes and pathophysiological mechanisms in osteolytic or osteosclerotic localizations. A review. Morphol. Bull. L'association Anat. 2011, 95, 65-75. [CrossRef] [PubMed]

4. Roodman, G.D. Mechanisms of bone metastasis. N. Engl. J. Med. 2004, 350, 1655-1664. [CrossRef]

5. Hinge, M.; Andersen, K.T.; Lund, T.; Jorgensen, H.B.; Holdgaard, P.C.; Ormstrup, T.E.; Ostergaard, L.L.; Plesner, T. Bone healing in multiple myeloma: A prospective evaluation of the impact of first-line anti-myeloma treatment. Haematologica 2016, 101, e419-e422. [CrossRef]

6. Silbermann, R.; Roodman, G.D. Current Controversies in the Management of Myeloma Bone Disease. J. Cell. Physiol. 2016, 231, 2374-2379. [CrossRef]

7. Roodman, G.D. Pathogenesis of myeloma bone disease. Blood Cells Mol. Dis. 2004, 32, 290-292. [CrossRef]

8. Aly, A.; Onukwugha, E.; Woods, C.; Mullins, C.D.; Kwok, Y.; Qian, Y.; Arellano, J.; Balakumaran, A.; Hussain, A. Measurement of skeletal related events in SEER-Medicare: A comparison of claims-based methods. BMC Med. Res. Methodol. 2015, 15, 65. [CrossRef]

9. Kim, C.; Bhatta, S.; Cyprien, L.; Fonseca, R.; Hernandez, R.K. Incidence of skeletal-related events among multiple myeloma patients in the United States at oncology clinics: Observations from real-world data. J. Bone. Oncol. 2019, 14, 100215. [CrossRef]

10. Sonmez, M.; Akagun, T.; Topbas, M.; Cobanoglu, U.; Sonmez, B.; Yilmaz, M.; Ovali, E.; Omay, S.B. Effect of pathologic fractures on survival in multiple myeloma patients: A case control study. J. Exp. Clin. Cancer Res. CR 2008, 27, 11. [CrossRef]

11. Ntanasis-Stathopoulos, I.; Fotiou, D.; Terpos, E. CCL3 Signaling in the Tumor Microenvironment. Adv. Exp. Med. Biol. 2020, 1231, 13-21. [PubMed]

12. Politou, M.; Terpos, E.; Anagnostopoulos, A.; Szydlo, R.; Laffan, M.; Layton, M.; Apperley, J.F.; Dimopoulos, M.A.; Rahemtulla, A. Role of receptor activator of nuclear factor-kappa B ligand (RANKL), osteoprotegerin and macrophage protein 1-alpha (MIP-1a) in monoclonal gammopathy of undetermined significance (MGUS). Br. J. Haematol. 2004, 126, 686-689. [CrossRef]

13. Terpos, E.; Szydlo, R.; Apperley, J.F.; Hatjiharissi, E.; Politou, M.; Meletis, J.; Viniou, N.; Yataganas, X.; Goldman, J.M.; Rahemtulla, A. Soluble receptor activator of nuclear factor kappaB ligand-osteoprotegerin ratio predicts survival in multiple myeloma: Proposal for a novel prognostic index. Blood 2003, 102, 1064-1069. [CrossRef] [PubMed]

14. Terpos, E.; Ntanasis-Stathopoulos, I.; Dimopoulos, M.A. Myeloma bone disease: From biology findings to treatment approaches. Blood 2019, 133, 1534-1539. [CrossRef] [PubMed]

15. Yen, C.H.; Hsiao, H.H. NRF2 Is One of the Players Involved in Bone Marrow Mediated Drug Resistance in Multiple Myeloma. Int. J. Mol. Sci. 2018, 19, 3503. [CrossRef] [PubMed]

16. Hadjidakis, D.J.; Androulakis, I.I. Bone remodeling. Ann. N. Y. Acad. Sci. 2006, 1092, 385-396. [CrossRef]

17. Raggatt, L.J.; Partridge, N.C. Cellular and molecular mechanisms of bone remodeling. J. Biol. Chem. 2010, 285, 25103-25108. [CrossRef]

18. Xiao, W.; Wang, Y.; Pacios, S.; Li, S.; Graves, D.T. Cellular and Molecular Aspects of Bone Remodeling. Front. Oral Biol. 2016, 18, 9-16.

19. Janckila, A.J.; Takahashi, K.; Sun, S.Z.; Yam, L.T. Naphthol-ASBI phosphate as a preferred substrate for tartrate-resistant acid phosphatase isoform 5b. J. Bone Miner. Res. Off. J. Am. Soc. Bone Miner. Res. 2001, 16, 788-793. [CrossRef]

20. Janckila, A.J.; Takahashi, K.; Sun, S.Z.; Yam, L.T. Tartrate-resistant acid phosphatase isoform $5 \mathrm{~b}$ as serum marker for osteoclastic activity. Clin. Chem. 2001, 47, 74-80. [CrossRef]

21. Nakagawa, N.; Kinosaki, M.; Yamaguchi, K.; Shima, N.; Yasuda, H.; Yano, K.; Morinaga, T.; Higashio, K. RANK is the essential signaling receptor for osteoclast differentiation factor in osteoclastogenesis. Biochem. Biophys. Res. Commun. 1998, 253, 395-400. [CrossRef] 
22. Takahashi, N.; Udagawa, N.; Suda, T. A new member of tumor necrosis factor ligand family, ODF/OPGL/TRANCE/RANKL, regulates osteoclast differentiation and function. Biochem. Biophys. Res. Commun. 1999, 256, 449-455. [CrossRef]

23. Chambers, T.J. Regulation of the differentiation and function of osteoclasts. J. Pathol. 2000, 192, 4-13. [CrossRef]

24. Kogianni, G.; Mann, V.; Noble, B.S. Apoptotic bodies convey activity capable of initiating osteoclastogenesis and localized bone destruction. J. Bone Miner. Res. Off. J. Am. Soc. Bone Miner. Res. 2008, 23, 915-927. [CrossRef]

25. Dougall, W.C.; Glaccum, M.; Charrier, K.; Rohrbach, K.; Brasel, K.; De Smedt, T.; Daro, E.; Smith, J.; Tometsko, M.E.; Maliszewski, C.R.; et al. RANK is essential for osteoclast and lymph node development. Genes Dev. 1999, 13, 2412-2424. [CrossRef]

26. Tsukii, K.; Shima, N.; Mochizuki, S.; Yamaguchi, K.; Kinosaki, M.; Yano, K.; Shibata, O.; Udagawa, N.; Yasuda, H.; Suda, T.; et al. Osteoclast differentiation factor mediates an essential signal for bone resorption induced by 1 alpha,25-dihydroxyvitamin D3, prostaglandin E2, or parathyroid hormone in the microenvironment of bone. Biochem. Biophys. Res. Commun. 1998, 246, 337-341. [CrossRef]

27. Qiang, Y.W.; Chen, Y.; Stephens, O.; Brown, N.; Chen, B.; Epstein, J.; Barlogie, B.; Shaughnessy, J.D.J. Myeloma-derived Dickkopf-1 disrupts Wnt-regulated osteoprotegerin and RANKL production by osteoblasts: A potential mechanism underlying osteolytic bone lesions in multiple myeloma. Blood 2008, 112, $196-207$. [CrossRef]

28. Weitzmann, M.N. Bone and the Immune System. Toxicol. Pathol. 2017, 45, 911-924. [CrossRef]

29. Zupan, J.; Komadina, R.; Marc, J. The relationship between osteoclastogenic and anti-osteoclastogenic pro-inflammatory cytokines differs in human osteoporotic and osteoarthritic bone tissues. J. Biomed. Sci. 2012, 19, 28. [CrossRef]

30. Boyce, B.F.; Xing, L. Functions of RANKL/RANK/OPG in bone modeling and remodeling. Arch. Biochem. Biophys. 2008, 473, 139-146. [CrossRef]

31. Hofbauer, L.C.; Khosla, S.; Dunstan, C.R.; Lacey, D.L.; Boyle, W.J.; Riggs, B.L. The roles of osteoprotegerin and osteoprotegerin ligand in the paracrine regulation of bone resorption. J. Bone Miner. Res. Off. J. Am. Soc. Bone Miner. Res. 2000, 15, 2-12. [CrossRef]

32. Huang, W.; Yang, S.; Shao, J.; Li, Y.P. Signaling and transcriptional regulation in osteoblast commitment and differentiation. Front. Biosci. A J. Virtual Libr. 2007, 12, 3068-3092. [CrossRef] [PubMed]

33. Chen, G.; Deng, C.; Li, Y.P. TGF- $\beta$ and BMP signaling in osteoblast differentiation and bone formation. Int. J. Biol. Sci. 2012, 8, 272-288. [CrossRef] [PubMed]

34. George, J.; Kuboki, Y.; Miyata, T. Differentiation of mesenchymal stem cells into osteoblasts on honeycomb collagen scaffolds. Biotechnol. Bioeng. 2006, 95, 404-411. [CrossRef] [PubMed]

35. Harada, S.; Rodan, G.A. Control of osteoblast function and regulation of bone mass. Nature 2003, 423, 349-355. [CrossRef] [PubMed]

36. Vallet, S.; Filzmoser, J.M.; Pecherstorfer, M.; Podar, K. Myeloma Bone Disease: Update on Pathogenesis and Novel Treatment Strategies. Pharmaceutics 2018, 10, 202. [CrossRef]

37. Chen, A.; Hamamura, K.; Zhang, P.; Chen, Y.; Yokota, H. Systems analysis of bone remodelling as a homeostatic regulator. IET Syst. Biol. 2010, 4, 52-63. [CrossRef]

38. O'Brien, C.A.; Nakashima, T.; Takayanagi, H. Osteocyte control of osteoclastogenesis. Bone 2013, 54, $258-263$. [CrossRef]

39. Florencio-Silva, R.; Sasso, G.R.; Sasso-Cerri, E.; Simões, M.J.; Cerri, P.S. Biology of Bone Tissue: Structure, Function, and Factors That Influence Bone Cells. Biomed Res. Int. 2015, 2015, 421746. [CrossRef]

40. Nakahama, K. Cellular communications in bone homeostasis and repair. Cell. Mol. Life Sci. CMLS 2010, 67, 4001-4009. [CrossRef]

41. Bonewald, L.F. The amazing osteocyte. J. Bone Miner. Res. Off. J. Am. Soc. Bone Miner. Res. 2011, 26, $229-238$. [CrossRef] [PubMed]

42. Tsourdi, E.; Jähn, K.; Rauner, M.; Busse, B.; Bonewald, L.F. Physiological and pathological osteocytic osteolysis. J. Musculoskelet. Neuronal Interact. 2018, 18, 292-303. [PubMed]

43. Giuliani, N.; Colla, S.; Rizzoli, V. Update on the pathogenesis of osteolysis in multiple myeloma patients. Acta Bio-Med. Atenei Parm. 2004, 75, 143-152. 
44. Giuliani, N.; Rizzoli, V.; Roodman, G.D. Multiple myeloma bone disease: Pathophysiology of osteoblast inhibition. Blood 2006, 108, 3992-3996. [CrossRef]

45. Roodman, G.D. Pathogenesis of myeloma bone disease. J. Cell. Biochem. 2010, 109, $283-291$.

46. Terpos, E.; Christoulas, D.; Gavriatopoulou, M. Biology and treatment of myeloma related bone disease. Metab. Clin. Exp. 2018, 80, 80-90. [CrossRef]

47. Christoulas, D.; Terpos, E.; Dimopoulos, M.A. Pathogenesis and management of myeloma bone disease. Expert Rev. Hematol. 2009, 2, 385-398. [CrossRef]

48. Gregory, C. MM-induced osteolysis: Partners in crime. Blood 2008, 112, 3-4. [CrossRef]

49. Teitelbaum, S.L.; Ross, F.P. Genetic regulation of osteoclast development and function. Nat. Rev. Genet. 2003, 4, 638-649. [CrossRef]

50. Boyle, W.J.; Simonet, W.S.; Lacey, D.L. Osteoclast differentiation and activation. Nature 2003, 423, 337-342. [CrossRef]

51. Theoleyre, S.; Wittrant, Y.; Tat, S.K.; Fortun, Y.; Redini, F.; Heymann, D. The molecular triad OPG/RANK/RANKL: Involvement in the orchestration of pathophysiological bone remodeling. Cytokine Growth Factor Rev. 2004, 15, 457-475. [CrossRef]

52. Graham, J.M.; Ayati, B.P.; Holstein, S.A.; Martin, J.A. The role of osteocytes in targeted bone remodeling: A mathematical model. PLoS ONE 2013, 8, e63884. [CrossRef]

53. Nakashima, T.; Hayashi, M.; Fukunaga, T.; Kurata, K.; Oh-Hora, M.; Feng, J.Q.; Bonewald, L.F.; Kodama, T.; Wutz, A.; Wagner, E.F.; et al. Evidence for osteocyte regulation of bone homeostasis through RANKL expression. Nat. Med. 2011, 17, 1231-1234. [CrossRef]

54. Kong, Y.Y.; Yoshida, H.; Sarosi, I.; Tan, H.L.; Timms, E.; Capparelli, C.; Morony, S.; Oliveira-dos-Santos, A.J.; Van, G.; Itie, A.; et al. OPGL is a key regulator of osteoclastogenesis, lymphocyte development and lymph-node organogenesis. Nature 1999, 397, 315-323. [CrossRef]

55. Nakashima, T.; Hayashi, M.; Takayanagi, H. New insights into osteoclastogenic signaling mechanisms. Trends Endocrinol. Metab. TEM 2012, 23, 582-590. [CrossRef]

56. Okamoto, K.; Nakashima, T.; Shinohara, M.; Negishi-Koga, T.; Komatsu, N.; Terashima, A.; Sawa, S.; Nitta, T.; Takayanagi, H. Osteoimmunology: The Conceptual Framework Unifying the Immune and Skeletal Systems. Physiol. Rev. 2017, 97, 1295-1349. [CrossRef]

57. Walsh, M.C.; Choi, Y. Biology of the RANKL-RANK-OPG System in Immunity, Bone, and Beyond. Front. Immunol. 2014, 5, 511. [CrossRef]

58. Chaweewannakorn, W.; Ariyoshi, W.; Okinaga, T.; Fujita, Y.; Maki, K.; Nishihara, T. Ameloblastin attenuates RANKL-mediated osteoclastogenesis by suppressing activation of nuclear factor of activated T-cell cytoplasmic 1 (NFATc1). J. Cell. Physiol. 2019, 234, 1745-1757. [CrossRef]

59. Liu, W.; Zhang, X. Receptor activator of nuclear factor-kB ligand (RANKL)/RANK/osteoprotegerin system in bone and other tissues (review). Mol. Med. Rep. 2015, 11, 3212-3218. [CrossRef]

60. Ono, T.; Hayashi, M.; Sasaki, F.; Nakashima, T. RANKL biology: Bone metabolism, the immune system, and beyond. Inflamm. Regen. 2020, 40, 2. [CrossRef]

61. Lacey, D.L.; Timms, E.; Tan, H.L.; Kelley, M.J.; Dunstan, C.R.; Burgess, T.; Elliott, R.; Colombero, A.; Elliott, G.; Scully, S.; et al. Osteoprotegerin ligand is a cytokine that regulates osteoclast differentiation and activation. Cell 1998, 93, 165-176. [CrossRef]

62. Kostenuik, P.J.; Shalhoub, V. Osteoprotegerin: A physiological and pharmacological inhibitor of bone resorption. Curr. Pharm. Des. 2001, 7, 613-635. [CrossRef]

63. Giuliani, N.; Colla, S.; Sala, R.; Moroni, M.; Lazzaretti, M.; La Monica, S.; Bonomini, S.; Hojden, M.; Sammarelli, G.; Barillè, S.; et al. Human myeloma cells stimulate the receptor activator of nuclear factor-kappa B ligand (RANKL) in T lymphocytes: A potential role in multiple myeloma bone disease. Blood 2002, 100, 4615-4621. [CrossRef]

64. Standal, T.; Seidel, C.; Hjertner, Ø.; Plesner, T.; Sanderson, R.D.; Waage, A.; Borset, M.; Sundan, A. Osteoprotegerin is bound, internalized, and degraded by multiple myeloma cells. Blood 2002, 100, 3002-3007. [CrossRef]

65. Delgado-Calle, J.; Anderson, J.; Cregor, M.D.; Hiasa, M.; Chirgwin, J.M.; Carlesso, N.; Yoneda, T.; Mohammad, K.S.; Plotkin, L.I.; Roodman, G.D.; et al. Bidirectional Notch Signaling and Osteocyte-Derived Factors in the Bone Marrow Microenvironment Promote Tumor Cell Proliferation and Bone Destruction in Multiple Myeloma. Cancer Res. 2016, 76, 1089-1100. [CrossRef] 
66. Giuliani, N.; Ferretti, M.; Bolzoni, M.; Storti, P.; Lazzaretti, M.; Dalla Palma, B.; Bonomini, S.; Martella, E.; Agnelli, L.; Neri, A.; et al. Increased osteocyte death in multiple myeloma patients: Role in myeloma-induced osteoclast formation. Leukemia 2012, 26, 1391-1401. [CrossRef] [PubMed]

67. Itoh, K.; Igarashi, K.; Hayashi, N.; Nishizawa, M.; Yamamoto, M. Cloning and characterization of a novel erythroid cell-derived CNC family transcription factor heterodimerizing with the small Maf family proteins. Mol. Cell. Biol. 1995, 15, 4184-4193. [CrossRef]

68. Motohashi, H.; O'Connor, T.; Katsuoka, F.; Engel, J.D.; Yamamoto, M. Integration and diversity of the regulatory network composed of Maf and CNC families of transcription factors. Gene 2002, 294, 1-12. [CrossRef]

69. Tian, W.; Rojo de la Vega, M.; Schmidlin, C.J.; Ooi, A.; Zhang, D.D. Kelch-like ECH-associated protein 1 (KEAP1) differentially regulates nuclear factor erythroid-2-related factors 1 and 2 (NRF1 and NRF2). J. Biol. Chem. 2018, 293, 2029-2040. [CrossRef]

70. Suzuki, T.; Yamamoto, M. Stress-sensing mechanisms and the physiological roles of the Keap1-Nrf2 system during cellular stress. J. Biol. Chem. 2017, 292, 16817-16824. [CrossRef]

71. Yamamoto, M.; Kensler, T.W.; Motohashi, H. The KEAP1-NRF2 System: A Thiol-Based Sensor-Effector Apparatus for Maintaining Redox Homeostasis. Physiol. Rev. 2018, 98, 1169-1203. [CrossRef] [PubMed]

72. Villeneuve, N.F.; Lau, A.; Zhang, D.D. Regulation of the Nrf2-Keap1 antioxidant response by the ubiquitin proteasome system: An insight into cullin-ring ubiquitin ligases. Antioxid. Redox Signal. 2010, 13, 1699-1712. [CrossRef] [PubMed]

73. Wu, T.; Zhao, F.; Gao, B.; Tan, C.; Yagishita, N.; Nakajima, T.; Wong, P.K.; Chapman, E.; Fang, D.; Zhang, D.D. Hrd1 suppresses Nrf2-mediated cellular protection during liver cirrhosis. Genes Dev. 2014, 28, 708-722. [CrossRef]

74. Panieri, E.; Saso, L. Potential Applications of NRF2 Inhibitors in Cancer Therapy. Oxid. Med. Cell Longev. 2019, 2019, 8592348. [CrossRef]

75. McMahon, M.; Itoh, K.; Yamamoto, M.; Chanas, S.A.; Henderson, C.J.; McLellan, L.I.; Wolf, C.R.; Cavin, C.; Hayes, J.D. The Cap'n'Collar basic leucine zipper transcription factor Nrf2 (NF-E2 p45-related factor 2) controls both constitutive and inducible expression of intestinal detoxification and glutathione biosynthetic enzymes. Cancer Res. 2001, 61, 3299-3307.

76. Nioi, P.; McMahon, M.; Itoh, K.; Yamamoto, M.; Hayes, J.D. Identification of a novel Nrf2-regulated antioxidant response element (ARE) in the mouse $\mathrm{NAD}(\mathrm{P}) \mathrm{H}$ :quinone oxidoreductase 1 gene: Reassessment of the ARE consensus sequence. Biochem. J. 2003, 374, 337-348. [CrossRef]

77. Pi, J.; Hayes, J.D.; Yamamoto, M. New insights into nuclear factor erythroid 2-related factors in toxicology and pharmacology. Toxicol. Appl. Pharmacol. 2019, 367, 33-35. [CrossRef]

78. Pi, J.; Freeman, M.L.; Yamamoto, M. Nrf2 in toxicology and pharmacology: The good, the bad and the ugly? Toxicol. Appl. Pharmacol. 2010, 244,1-3. [CrossRef]

79. Lacher, S.E.; Lee, J.S.; Wang, X.; Campbell, M.R.; Bell, D.A.; Slattery, M. Beyond antioxidant genes in the ancient Nrf2 regulatory network. Free Radic. Biol. Med. 2015, 88, 452-465. [CrossRef]

80. Marini, M.G.; Asunis, I.; Chan, K.; Chan, J.Y.; Kan, Y.W.; Porcu, L.; Cao, A.; Moi, P. Cloning MafF by recognition site screening with the NFE2 tandem repeat of HS2: Analysis of its role in globin and GCSl genes regulation. Blood Cells Mol. Dis. 2002, 29, 145-158. [CrossRef]

81. Marini, M.G.; Chan, K.; Casula, L.; Kan, Y.W.; Cao, A.; Moi, P. hMAF, a small human transcription factor that heterodimerizes specifically with Nrf1 and Nrf2. J. Biol. Chem. 1997, 272, 16490-16497. [CrossRef]

82. Wang, X.; Tomso, D.J.; Chorley, B.N.; Cho, H.Y.; Cheung, V.G.; Kleeberger, S.R.; Bell, D.A. Identification of polymorphic antioxidant response elements in the human genome. Hum. Mol. Genet. 2007, 16, 1188-1200. [CrossRef] [PubMed]

83. Dhakshinamoorthy, S.; Jain, A.K.; Bloom, D.A.; Jaiswal, A.K. Bach1 competes with Nrf2 leading to negative regulation of the antioxidant response element (ARE)-mediated $\mathrm{NAD}(\mathrm{P}) \mathrm{H}$ :quinone oxidoreductase 1 gene expression and induction in response to antioxidants. J. Biol. Chem. 2005, 280, 16891-16900. [CrossRef]

84. Jeyapaul, J.; Jaiswal, A.K. Nrf2 and c-Jun regulation of antioxidant response element (ARE)-mediated expression and induction of gamma-glutamylcysteine synthetase heavy subunit gene. Biochem. Pharmacol. 2000, 59, 1433-1439. [CrossRef] 
85. Itoh, K.; Wakabayashi, N.; Katoh, Y.; Ishii, T.; O'Connor, T.; Yamamoto, M. Keap1 regulates both cytoplasmic-nuclear shuttling and degradation of Nrf2 in response to electrophiles. Genes Cells Devoted Mol. Cell. Mech. 2003, 8, 379-391. [CrossRef]

86. Nguyen, T.; Sherratt, P.J.; Nioi, P.; Yang, C.S.; Pickett, C.B. Nrf2 controls constitutive and inducible expression of ARE-driven genes through a dynamic pathway involving nucleocytoplasmic shuttling by Keap1. J. Biol. Chem. 2005, 280, 32485-32492. [CrossRef]

87. Chowdhry, S.; Zhang, Y.; McMahon, M.; Sutherland, C.; Cuadrado, A.; Hayes, J.D. Nrf2 is controlled by two distinct $\beta$-TrCP recognition motifs in its Neh6 domain, one of which can be modulated by GSK-3 activity. Oncogene 2013, 32, 3765-3781. [CrossRef]

88. Rada, P.; Rojo, A.I.; Evrard-Todeschi, N.; Innamorato, N.G.; Cotte, A.; Jaworski, T.; Tobón-Velasco, J.C.; Devijver, H.; García-Mayoral, M.F.; Van Leuven, F.; et al. Structural and functional characterization of Nrf2 degradation by the glycogen synthase kinase 3/ $\beta$-TrCP axis. Mol. Cell. Biol. 2012, 32, 3486-3499. [CrossRef]

89. Rada, P.; Rojo, A.I.; Chowdhry, S.; McMahon, M.; Hayes, J.D.; Cuadrado, A. SCF/\{beta\}-TrCP promotes glycogen synthase kinase 3-dependent degradation of the Nrf2 transcription factor in a Keap1-independent manner. Mol. Cell. Biol. 2011, 31, 1121-1133. [CrossRef]

90. Lau, A.; Wang, X.J.; Zhao, F.; Villeneuve, N.F.; Wu, T.; Jiang, T.; Sun, Z.; White, E.; Zhang, D.D. A noncanonical mechanism of Nrf2 activation by autophagy deficiency: Direct interaction between Keap1 and p62. Mol. Cell. Biol. 2010, 30, 3275-3285. [CrossRef]

91. Jain, A.; Lamark, T.; Sjottem, E.; Larsen, K.B.; Awuh, J.A.; Overvatn, A.; McMahon, M.; Hayes, J.D.; Johansen, T. p62/SQSTM1 is a target gene for transcription factor NRF2 and creates a positive feedback loop by inducing antioxidant response element-driven gene transcription. J. Biol. Chem. 2010, 285, 22576-22591. [CrossRef] [PubMed]

92. Kizaki, M.; Tabayashi, T. The Role of Intracellular Signaling Pathways in the Pathogenesis of Multiple Myeloma and Novel Therapeutic Approaches. J. Clin. Exp. Hematop. JCEH 2016, 56, 20-27. [CrossRef]

93. Manni, S.; Carrino, M.; Semenzato, G.; Piazza, F. Old and Young Actors Playing Novel Roles in the Drama of Multiple Myeloma Bone Marrow Microenvironment Dependent Drug Resistance. Int. J. Mol. Sci. 2018, 19, 19. [CrossRef]

94. Shay, G.; Hazlehurst, L.; Lynch, C.C. Dissecting the multiple myeloma-bone microenvironment reveals new therapeutic opportunities. J. Mol. Med. 2016, 94, 21-35. [CrossRef]

95. Mondello, P.; Cuzzocrea, S.; Navarra, M.; Mian, M. Bone marrow micro-environment is a crucial player for myelomagenesis and disease progression. Oncotarget 2017, 8, 20394-20409. [CrossRef]

96. Andrews, S.W.; Kabrah, S.; May, J.E.; Donaldson, C.; Morse, H.R. Multiple myeloma: The bone marrow microenvironment and its relation to treatment. Br. J. Biomed. Sci. 2013, 70, 110-120. [CrossRef]

97. Taniguchi, K.; Karin, M. IL-6 and related cytokines as the critical lynchpins between inflammation and cancer. Semin. Immunol. 2014, 26, 54-74. [CrossRef] [PubMed]

98. Nakashima, T.; Kobayashi, Y.; Yamasaki, S.; Kawakami, A.; Eguchi, K.; Sasaki, H.; Sakai, H. Protein expression and functional difference of membrane-bound and soluble receptor activator of NF-kappaB ligand: Modulation of the expression by osteotropic factors and cytokines. Biochem. Biophys. Res. Commun. 2000, 275, 768-775. [CrossRef]

99. Taniguchi, K.; Karin, M. NF-кB, inflammation, immunity and cancer: Coming of age. Nat. Rev. Immunol. 2018, 18, 309-324. [CrossRef]

100. Buelna-Chontal, M.; Zazueta, C. Redox activation of Nrf2 \& NF-kB: A double end sword? Cell. Signal. 2013, $25,2548-2557$.

101. Zhang, F.; Peng, W.; Zhang, J.; Dong, W.; Yuan, D.; Zheng, Y.; Wang, Z. New strategy of bone marrow mesenchymal stem cells against oxidative stress injury via Nrf2 pathway: Oxidative stress preconditioning. J. Cell. Biochem. 2019, 120, 19902-19914. [CrossRef] [PubMed]

102. Hyeon, S.; Lee, H.; Yang, Y.; Jeong, W. Nrf2 deficiency induces oxidative stress and promotes RANKL-induced osteoclast differentiation. Free Radic. Biol. Med. 2013, 65, 789-799. [CrossRef] [PubMed]

103. Piddock, R.E.; Marlein, C.R.; Abdul-Aziz, A.; Shafat, M.S.; Auger, M.J.; Bowles, K.M.; Rushworth, S.A. Myeloma-derived macrophage inhibitory factor regulates bone marrow stromal cell-derived IL-6 via c-MYC. J. Hematol. Oncol. 2018, 11, 66. [CrossRef] 
104. Thimmulappa, R.K.; Lee, H.; Rangasamy, T.; Reddy, S.P.; Yamamoto, M.; Kensler, T.W.; Biswal, S. Nrf2 is a critical regulator of the innate immune response and survival during experimental sepsis. J. Clin. Investig. 2006, 116, 984-995. [CrossRef]

105. Hengeveld, P.J.; Kersten, M.J. B-cell activating factor in the pathophysiology of multiple myeloma: A target for therapy? Blood Cancer J. 2015, 5, e282. [CrossRef]

106. Shen, X.; Guo, Y.; Yu, J.; Qi, J.; Shi, W.; Wu, X.; Ni, H.; Ju, S. miRNA-202 in bone marrow stromal cells affects the growth and adhesion of multiple myeloma cells by regulating B cell-activating factor. Clin. Exp. Med. 2016, 16, 307-316. [CrossRef]

107. Li, W.; Suwanwela, N.C.; Patumraj, S. Curcumin by down-regulating NF-kB and elevating Nrf2, reduces brain edema and neurological dysfunction after cerebral I/R. Microvasc. Res. 2016, 106, 117-127. [CrossRef]

108. Riz, I.; Hawley, T.S.; Marsal, J.W.; Hawley, R.G. Noncanonical SQSTM1/p62-Nrf2 pathway activation mediates proteasome inhibitor resistance in multiple myeloma cells via redox, metabolic and translational reprogramming. Oncotarget 2016, 7, 66360-66385. [CrossRef] [PubMed]

109. Sun, Y.X.; Xu, A.H.; Yang, Y.; Li, J. Role of Nrf2 in bone metabolism. J. Biomed. Sci. 2015, 22, 101. [CrossRef]

110. Sun, Y.; Abdul Aziz, A.; Bowles, K.; Rushworth, S. High NRF2 expression controls endoplasmic reticulum stress induced apoptosis in multiple myeloma. Cancer Lett 2018, 412, 37-45. [CrossRef]

111. Taguchi, K.; Yamamoto, M. The KEAP1-NRF2 System in Cancer. Front. Oncol 2017, 7, 85. [CrossRef]

112. Sun, Y.X.; Li, L.; Corry, K.A.; Zhang, P.; Yang, Y.; Himes, E.; Mihuti, C.L.; Nelson, C.; Dai, G.; Li, J. Deletion of $\mathrm{Nrf} 2$ reduces skeletal mechanical properties and decreases load-driven bone formation. Bone 2015, 74, 1-9. [CrossRef]

113. Pellegrini, G.G.; Cregor, M.; McAndrews, K.; Morales, C.C.; McCabe, L.D.; McCabe, G.P.; Peacock, M.; Burr, D.; Weaver, C.; Bellido, T. Nrf2 regulates mass accrual and the antioxidant endogenous response in bone differently depending on the sex and age. PLOS ONE 2017, 12, e0171161. [CrossRef]

114. Zhou, H.; Newnum, A.B.; Martin, J.R.; Li, P.; Nelson, M.T.; Moh, A.; Fu, X.Y.; Yokota, H.; Li, J. Osteoblast/osteocyte-specific inactivation of Stat3 decreases load-driven bone formation and accumulates reactive oxygen species. Bone 2011, 49, 404-411. [CrossRef]

115. Delgado-Calle, J.; Bellido, T.; Roodman, G.D. Role of osteocytes in multiple myeloma bone disease. Curr. Opin. Supportive Palliat. Care 2014, 8, 407-413. [CrossRef]

116. Romas, E.; Gillespie, M.T.; Martin, T.J. Involvement of receptor activator of NFkappaB ligand and tumor necrosis factor-alpha in bone destruction in rheumatoid arthritis. Bone 2002, 30, 340-346. [CrossRef]

117. Kanzaki, H.; Shinohara, F.; Kajiya, M.; Kodama, T. The Keap1/Nrf2 protein axis plays a role in osteoclast differentiation by regulating intracellular reactive oxygen species signaling. J. Biol. Chem. 2013, 288, 23009-23020. [CrossRef]

118. Xu, H.; Liu, T.; Li, J.; Xu, J.; Chen, F.; Hu, L.; Zhang, B.; Zi, C.; Wang, X.; Sheng, J. Oxidation derivative of (-)-epigallocatechin-3-gallate (EGCG) inhibits RANKL-induced osteoclastogenesis by suppressing RANK signaling pathways in RAW 264.7 cells. Biomed. Pharmacother. Biomed. Pharmacother. 2019, 118, 109237. [CrossRef]

119. Kanzaki, H.; Shinohara, F.; Itohiya, K.; Yamaguchi, Y.; Katsumata, Y.; Matsuzawa, M.; Fukaya, S.; Miyamoto, Y.; Wada, S.; Nakamura, Y. RANKL induces Bach1 nuclear import and attenuates Nrf2-mediated antioxidant enzymes, thereby augmenting intracellular reactive oxygen species signaling and osteoclastogenesis in mice. FASEB J. Off. Publ. Fed. Am. Soc. Exp. Biol. 2017, 31, 781-792. [CrossRef]

120. Kanzaki, H.; Shinohara, F.; Kanako, I.; Yamaguchi, Y.; Fukaya, S.; Miyamoto, Y.; Wada, S.; Nakamura, Y. Molecular regulatory mechanisms of osteoclastogenesis through cytoprotective enzymes. Redox Biol. 2016, 8 , 186-191. [CrossRef]

121. Rana, T.; Schultz, M.A.; Freeman, M.L.; Biswas, S. Loss of Nrf2 accelerates ionizing radiation-induced bone loss by upregulating RANKL. Free Radic. Biol. Med. 2012, 53, 2298-2307. [CrossRef] [PubMed]

122. Narimiya, T.; Kanzaki, H.; Yamaguchi, Y.; Wada, S.; Katsumata, Y.; Tanaka, K.; Tomonari, H. Nrf2 activation in osteoblasts suppresses osteoclastogenesis via inhibiting IL-6 expression. BONE Rep. 2019, 11, 100228. [CrossRef] [PubMed]

123. Park, C.K.; Lee, Y.; Kim, K.H.; Lee, Z.H.; Joo, M.; Kim, H.H. Nrf2 is a novel regulator of bone acquisition. BONE 2014, 63, 36-46. [CrossRef] 
124. Asagiri, M.; Sato, K.; Usami, T.; Ochi, S.; Nishina, H.; Yoshida, H.; Morita, I.; Wagner, E.F.; Mak, T.W.; Serfling, E.; et al. Autoamplification of NFATc1 expression determines its essential role in bone homeostasis. J. Exp. Med. 2005, 202, 1261-1269. [CrossRef] [PubMed]

125. Lee, H.I.; Lee, G.R.; Lee, J.; Kim, N.; Kwon, M.; Kim, H.J.; Kim, N.Y.; Park, J.H.; Jeong, W. Dehydrocostus lactone inhibits NFATc1 via regulation of IKK, JNK, and Nrf2, thereby attenuating osteoclastogenesis. $B M B$ Rep. 2020, 53, 218-222. [CrossRef]

126. Lee, H.I.; Lee, J.; Hwang, D.; Lee, G.R.; Kim, N.; Kwon, M.; Lee, H.; Piao, D.; Kim, H.J.; Kim, N.Y.; et al. Dehydrocostus lactone suppresses osteoclast differentiation by regulating NFATc1 and inhibits osteoclast activation through modulating migration and lysosome function. Faseb J. Off. Publ. Fed. Am. Soc. Exp. Biol. 2019, 33, 9685-9694. [CrossRef]

127. Lee, S.Y.; Lee, K.S.; Yi, S.H.; Kook, S.H.; Lee, J.C. Acteoside suppresses RANKL-mediated osteoclastogenesis by inhibiting c-Fos induction and NF-kB pathway and attenuating ROS production. PLoS ONE 2013,8, e80873. [CrossRef]

128. Takayanagi, H. The role of NFAT in osteoclast formation. Ann. N. Y. Acad. Sci. 2007, 1116, 227-237. [CrossRef]

129. Gangemi, S.; Allegra, A.; Alonci, A.; Cristani, M.; Russo, S.; Speciale, A.; Penna, G.; Spatari, G.; Cannavo, A.; Bellomo, G.; et al. Increase of novel biomarkers for oxidative stress in patients with plasma cell disorders and in multiple myeloma patients with bone lesions. Inflamm. Res. Off. J. Eur. Histamine Res. Soc. 2012, 61, 1063-1067. [CrossRef]

130. Hinoi, E.; Fujimori, S.; Wang, L.; Hojo, H.; Uno, K.; Yoneda, Y. Nrf2 negatively regulates osteoblast differentiation via interfering with Runx2-dependent transcriptional activation. J. Biol. Chem. 2006, 281, 18015-18024. [CrossRef]

131. Komori, T. Regulation of bone development and extracellular matrix protein genes by RUNX2. Cell Tissue Res. 2010, 339, 189-195. [CrossRef]

132. Ducy, P.; Starbuck, M.; Priemel, M.; Shen, J.; Pinero, G.; Geoffroy, V.; Amling, M.; Karsenty, G. A Cbfa1-dependent genetic pathway controls bone formation beyond embryonic development. Genes Dev. 1999, 13, 1025-1036. [CrossRef]

133. Komori, T.; Yagi, H.; Nomura, S.; Yamaguchi, A.; Sasaki, K.; Deguchi, K.; Shimizu, Y.; Bronson, R.T.; Gao, Y.H.; Inada, M.; et al. Targeted disruption of $\mathrm{Cbfa} 1$ results in a complete lack of bone formation owing to maturational arrest of osteoblasts. Cell 1997, 89, 755-764. [CrossRef]

134. Inada, M.; Yasui, T.; Nomura, S.; Miyake, S.; Deguchi, K.; Himeno, M.; Sato, M.; Yamagiwa, H.; Kimura, T.; Yasui, N.; et al. Maturational disturbance of chondrocytes in Cbfa1-deficient mice. Dev. Dyn. Off. Publ. Am. Assoc. Anat. 1999, 214, 279-290.

135. Komori, T. Roles of Runx2 in Skeletal Development. Adv. Exp. Med. Biol. 2017, 962, 83-93.

136. Zhang, S.; Xiao, Z.; Luo, J.; He, N.; Mahlios, J.; Quarles, L.D. Dose-dependent effects of Runx2 on bone development. J. Bone Miner. Res. Off. J. Am. Soc. Bone Miner. Res. 2009, 24, 1889-1904. [CrossRef] [PubMed]

137. Holmstrom, K.M.; Kostov, R.V.; Dinkova-Kostova, A.T. The multifaceted role of Nrf2 in mitochondrial function. Curr. Opin. Toxicol. 2016, 1, 80-91. [CrossRef]

138. Ryoo, I.G.; Kwak, M.K. Regulatory crosstalk between the oxidative stress-related transcription factor Nfe212/Nrf2 and mitochondria. Toxicol. Appl. Pharmacol. 2018, 359, 24-33. [CrossRef]

139. Shadel, G.S.; Horvath, T.L. Mitochondrial ROS signaling in organismal homeostasis. Cell 2015, 163, 560-569. [CrossRef]

140. Wu, K.C.; Cui, J.Y.; Klaassen, C.D. Beneficial role of Nrf2 in regulating NADPH generation and consumption. Toxicol. Sci. Off. J. Soc. Toxicol. 2011, 123, 590-600. [CrossRef]

141. Popov, L.D. Mitochondrial biogenesis: An update. J. Cell. Mol. Med. 2020, 24, 4892-4899. [CrossRef]

142. Piantadosi, C.A.; Carraway, M.S.; Babiker, A.; Suliman, H.B. Heme oxygenase-1 regulates cardiac mitochondrial biogenesis via Nrf2-mediated transcriptional control of nuclear respiratory factor-1. Circ. Res. 2008, 103, 1232-1240. [CrossRef]

143. Wu, K.L.H.; Wu, C.W.; Chao, Y.M.; Hung, C.Y.; Chan, J.Y.H. Impaired Nrf2 regulation of mitochondrial biogenesis in rostral ventrolateral medulla on hypertension induced by systemic inflammation. Free Radic. Biol. Med. 2016, 97, 58-74. [CrossRef]

144. Dinkova-Kostova, A.T.; Abramov, A.Y. The emerging role of Nrf2 in mitochondrial function. Free Radic. Biol. Med. 2015, 88, 179-188. [CrossRef] 
145. Holmstrom, K.M.; Baird, L.; Zhang, Y.; Hargreaves, I.; Chalasani, A.; Land, J.M.; Stanyer, L.; Yamamoto, M.; Dinkova-Kostova, A.T.; Abramov, A.Y. Nrf2 impacts cellular bioenergetics by controlling substrate availability for mitochondrial respiration. Biol. Open 2013, 2, 761-770. [CrossRef]

146. Ludtmann, M.H.; Angelova, P.R.; Zhang, Y.; Abramov, A.Y.; Dinkova-Kostova, A.T. Nrf2 affects the efficiency of mitochondrial fatty acid oxidation. Biochem. J. 2014, 457, 415-424. [CrossRef]

147. Pang, S.; Lynn, D.A.; Lo, J.Y.; Paek, J.; Curran, S.P. SKN-1 and Nrf2 couples proline catabolism with lipid metabolism during nutrient deprivation. Nat. Commun. 2014, 5, 5048. [CrossRef]

148. Sharma, R.S.; Harrison, D.J.; Kisielewski, D.; Cassidy, D.M.; McNeilly, A.D.; Gallagher, J.R.; Walsh, S.V.; Honda, T.; McCrimmon, R.J.; Dinkova-Kostova, A.T.; et al. Experimental Nonalcoholic Steatohepatitis and Liver Fibrosis Are Ameliorated by Pharmacologic Activation of Nrf2 (NF-E2 p45-Related Factor 2). Cell. Mol. Gastroenterol. Hepatol. 2018, 5, 367-398. [CrossRef]

149. Kang, T.C. Nuclear Factor-Erythroid 2-Related Factor 2 (Nrf2) and Mitochondrial Dynamics/Mitophagy in Neurological Diseases. Antioxidants 2020, 9, 617. [CrossRef]

150. Pickles, S.; Vigie, P.; Youle, R.J. Mitophagy and Quality Control Mechanisms in Mitochondrial Maintenance. Curr. Biol. CB 2018, 28, R170-R185. [CrossRef]

151. Xiao, L.; Xu, X.; Zhang, F.; Wang, M.; Xu, Y.; Tang, D.; Wang, J.; Qin, Y.; Liu, Y.; Tang, C.; et al. The mitochondria-targeted antioxidant MitoQ ameliorated tubular injury mediated by mitophagy in diabetic kidney disease via Nrf2/PINK1. Redox Biol. 2017, 11, 297-311. [CrossRef] [PubMed]

152. Zheng, C.X.; Sui, B.D.; Qiu, X.Y.; Hu, C.H.; Jin, Y. Mitochondrial Regulation of Stem Cells in Bone Homeostasis. Trends Mol. Med. 2020, 26, 89-104. [CrossRef] [PubMed]

153. Schell, J.C.; Wisidagama, D.R.; Bensard, C.; Zhao, H.; Wei, P.; Tanner, J.; Flores, A.; Mohlman, J.; Sorensen, L.K.; Earl, C.S.; et al. Control of intestinal stem cell function and proliferation by mitochondrial pyruvate metabolism. Nat. Cell Biol. 2017, 19, 1027-1036. [CrossRef]

154. Snoeck, H.W. Mitochondrial regulation of hematopoietic stem cells. Curr. Opin. Cell Biol. 2017, 49, 91-98. [CrossRef]

155. Chen, C.T.; Shih, Y.R.; Kuo, T.K.; Lee, O.K.; Wei, Y.H. Coordinated changes of mitochondrial biogenesis and antioxidant enzymes during osteogenic differentiation of human mesenchymal stem cells. Stem Cells 2008, 26, 960-968. [CrossRef]

156. Gao, J.; Feng, Z.; Wang, X.; Zeng, M.; Liu, J.; Han, S.; Xu, J.; Chen, L.; Cao, K.; Long, J.; et al. SIRT3/SOD2 maintains osteoblast differentiation and bone formation by regulating mitochondrial stress. Cell Death Differ. 2018, 25, 229-240. [CrossRef]

157. Treiber, N.; Maity, P.; Singh, K.; Kohn, M.; Keist, A.F.; Ferchiu, F.; Sante, L.; Frese, S.; Bloch, W.; Kreppel, F.; et al. Accelerated aging phenotype in mice with conditional deficiency for mitochondrial superoxide dismutase in the connective tissue. Aging Cell 2011, 10, 239-254. [CrossRef]

158. Liu, S.; Yang, L.; Mu, S.; Fu, Q. Epigallocatechin-3-Gallate Ameliorates Glucocorticoid-Induced Osteoporosis of Rats in Vivo and in Vitro. Front. Pharmacol. 2018, 9, 447. [CrossRef]

159. Tang, X.; Ma, S.; Li, Y.; Sun, Y.; Zhang, K.; Zhou, Q.; Yu, R. Evaluating the Activity of Sodium Butyrate to Prevent Osteoporosis in Rats by Promoting Osteal GSK-3beta/Nrf2 Signaling and Mitochondrial Function. J. Agric. Food Chem. 2020, 68, 6588-6603. [CrossRef]

160. Zeng, R.; Faccio, R.; Novack, D.V. Alternative NF-kappaB Regulates RANKL-Induced Osteoclast Differentiation and Mitochondrial Biogenesis via Independent Mechanisms. J. Bone Miner. Res. Off. J. Am. Soc. Bone Miner. Res. 2015, 30, 2287-2299. [CrossRef]

161. Jin, Z.; Wei, W.; Yang, M.; Du, Y.; Wan, Y. Mitochondrial complex I activity suppresses inflammation and enhances bone resorption by shifting macrophage-osteoclast polarization. Cell Metab. 2014, 20, 483-498. [CrossRef] [PubMed]

162. Kim, H.; Lee, Y.D.; Kim, H.J.; Lee, Z.H.; Kim, H.H. SOD2 and Sirt3 Control Osteoclastogenesis by Regulating Mitochondrial ROS. J. Bone Miner. Res. Off. J. Am. Soc. Bone Miner. Res. 2017, 32, 397-406. [CrossRef] [PubMed]

163. Bartell, S.M.; Kim, H.N.; Ambrogini, E.; Han, L.; Iyer, S.; Serra Ucer, S.; Rabinovitch, P.; Jilka, R.L.; Weinstein, R.S.; Zhao, H.; et al. FoxO proteins restrain osteoclastogenesis and bone resorption by attenuating $\mathrm{H}_{2} \mathrm{O}_{2}$ accumulation. Nat. Commun. 2014, 5, 3773. [CrossRef] [PubMed]

164. Yu, S.L.Z.; Manar, S.; Shafat, K.; Bowles, M.; Rushworth, S.A. Dual Activation of NRF2 in Multiple Myeloma and Bone Marrow Mesenchymal Stromal Cells Regulates Chemotherapy Resistance. Blood 2016, 128, 3287. 
165. Liu, H.Y.; Tuckett, A.Z.; Fennell, M.; Garippa, R.; Zakrzewski, J.L. Repurposing of the CDK inhibitor PHA-767491 as a NRF2 inhibitor drug candidate for cancer therapy via redox modulation. Invest. New Drugs 2018, 36, 590-600. [CrossRef]

166. Harder, B.; Tian, W.; La Clair, J.J.; Tan, A.C.; Ooi, A.; Chapman, E.; Zhang, D.D. Brusatol overcomes chemoresistance through inhibition of protein translation. Mol. Carcinog. 2017, 56, 1493-1500. [CrossRef]

167. Song, I.S.; Kim, H.K.; Lee, S.R.; Jeong, S.H.; Kim, N.; Ko, K.S.; Rhee, B.D.; Han, J. Mitochondrial modulation decreases the bortezomib-resistance in multiple myeloma cells. Int. J. Cancer 2013, 133, 1357-1367. [CrossRef]

168. Zhan, X.; Yu, W.; Franqui-Machin, R.; Bates, M.L.; Nadiminti, K.; Cao, H.; Amendt, B.A.; Jethava, Y.; Frech, I.; Zhan, F.; et al. Alteration of mitochondrial biogenesis promotes disease progression in multiple myeloma. Oncotarget 2017, 8, 111213-111224. [CrossRef]

169. Ortiz-Ruiz, A.; Ruiz-Heredia, Y.; Samur, M.; Aguilar-Garrido, P.; Morales, M.L.; Valeri, A.; Garcia-Ortiz, A.; Barrio, S.; Bárcena, C.; Garcia-Martin, R.M. Increase of Mitochondrial Activity Contributes to the Bortezomib-Relapsed in Multiple Myeloma, a Novel Therapeutic Opportunity; American Society of Hematology: Washington, DC, USA, 2019.

170. Mitsuishi, Y.; Motohashi, H.; Yamamoto, M. The Keap1-Nrf2 system in cancers: Stress response and anabolic metabolism. Front. Oncol. 2012, 2, 200. [CrossRef]

171. Wang, Y.-Y.; Yang, Y.-X.; Zhe, H.; He, Z.-X.; Zhou, S.-F. Bardoxolone methyl (CDDO-Me) as a therapeutic agent: An update on its pharmacokinetic and pharmacodynamic properties. Drug Des. Dev. Ther. 2014, 8, 2075-2088.

(C) 2020 by the authors. Licensee MDPI, Basel, Switzerland. This article is an open access article distributed under the terms and conditions of the Creative Commons Attribution (CC BY) license (http://creativecommons.org/licenses/by/4.0/). 